\title{
Cilostazol attenuates hepatic stellate cell activation and protects mice against carbon tetrachloride- induced liver fibrosis.
}

\section{$\operatorname{AUTHOR}(\mathrm{S}):$}

Saito, Shunichi; Hata, Koichiro; Iwaisako, Keiko; Yanagida, Atsuko; Takeiri, Masatoshi; Tanaka, Hirokazu; Kageyama, Shoichi; ... Ikeda, Kazuo; Asagiri, Masataka; Uemoto, Shinji

\section{CITATION:}

Saito, Shunichi ... [et al]. Cilostazol attenuates hepatic stellate cell activation and protects mice against carbon tetrachloride-induced liver fibrosis.. Hepatology research 2013, 44(4): 460-473

\section{ISSUE DATE:}

2013-06-30

\section{URL:}

http://hdl.handle.net/2433/198831

\section{RIGHT:}

This is the peer reviewed version of the following article: Saito, S., Hata, K., Iwaisako, K., Yanagida, A., Takeiri, M., Tanaka, H., Kageyama, S., Hirao, H., Ikeda, K., Asagiri, M. and Uemoto, S. (2014), Cilostazol attenuates hepatic stellate cell activation and protects mice against carbon tetrachloride-induced liver fibrosis. Hepatology Research, 44: 460-473, which has been published in final form at http://dx.doi.org/10.1111/hepr.12140. This article may be used for noncommercial purposes in accordance with Wiley Terms and Conditions for Self-Archiving.; This is not the published version. Please cite only the published version.; この論文は出版社版でありません。引用の際には出版社版をご確認ご 利用ください。 
Cilostazol attenuates hepatic stellate cell activation and protects mice against carbon tetrachloride-induced liver fibrosis

Running title: Cilostazol attenuates liver fibrosis

Shunichi Saito, ${ }^{\mathbf{1}}$ Koichiro Hata, ${ }^{1}{ }^{*}{ }^{*}$ Keiko Iwaisako, ${ }^{\mathbf{1}}{ }^{3}$ Atsuko Yanagida, ${ }^{1}$ Masatoshi Takeiri, ${ }^{2}$ Hirokazu Tanaka, ${ }^{1}$ Shoichi Kageyama, ${ }^{1}$ Hirofumi Hirao, ${ }^{1}$ Kazuo Ikeda, ${ }^{3}$ Masataka Asagiri $^{2,}{ }^{*}$ and Shinji Uemoto ${ }^{1}$

${ }^{1}$ Department of Surgery, Division of Hepato-Pancreato-Biliary Surgery and Transplantation, and 2Innovation Center for Immunoregulation and Therapeutics, Graduate School of Medicine, Kyoto University, Kyoto, Japan

${ }^{3}$ Department of Anatomy and Regenerative Biology, Graduate School of medicine, Osaka City University, Osaka, Japan

\section{*Address for Correspondence:}

Koichiro Hata, M.D., Ph.D.

Department of Surgery, Division of Hepato-Pancreato-Biliary Surgery and Transplantation, Kyoto University Graduate School of Medicine, Kawahara-cho 54, 
Shogoin, Sakyo-ku, Kyoto city, Kyoto 606-8507, Japan.

TEL: +81-75-751-4323, FAX: +81-75-751-4348

E-mail: khata@kuhp.kyoto-u.ac.jp

Masataka Asagiri, Ph.D., M.H.Sc.

Innovation Center for Immunoregulation and Therapeutics, Graduate School of Medicine,

Kyoto University, Yoshida Konoe, Sakyo-ku, Kyoto 606-8501, Japan

TEL: +81-75-753-9502, FAX: +81-75-753-9500

E-mail: masagiri@ak.med.kyoto-u.ac.jp 


\section{Abstract}

Background: Liver fibrosis is a common pathway leading to cirrhosis. Cilostazol, a

clinically-available oral phosphodiesterase-3 inhibitor, was shown to have an

antifibrotic potential in experimental non-alcoholic fatty liver disease. However, the detailed mechanisms of its antifibrotic effect and the efficacy in a different experimental model are elusive.

Methods: Male C57BL/6J mice were randomly assigned into five groups: control mice fed with normal diet (Group-1 and -2); mice fed with $0.1 \%$ and $0.3 \%$ cilostazol diet (Group-3 and -4, respectively), and with $0.125 \%$ clopidogrel (Group-5) as an anti-platelet drug control. After two weeks from the feeding, we injected carbon tetrachloride $\left(\mathrm{CCl}_{4}\right)$ intraperitoneally twice a week for six weeks into Group-2 to -5 mice. Group-1 was treated with only the vehicle. To clarify whether cilostazol has a direct effect on hepatic cells or not, we employed an in vitro study using primary-cultured HSCs, Kupffer cells or hepatocytes with cilostazol supplementation. Results: Sirius-red staining demonstrated Group-3 and -4 mice exhibited less fibrotic area (2.49 $\pm 0.43 \%$ and $2.31 \pm 0.30 \%$, respectively) than Group-2 mice $(3.17 \pm 0.67 \%$, $p<0.05$ and $p<0.001$, respectively). In vitro study revealed activation markers of HSC, namely $\alpha$-SMA, collagen- $\alpha 1(\mathrm{I})$ and PDGFR- $\beta$, were all lowered by cilostazol 
dose-dependently, suggesting their direct effect to attenuate HSC activation.

Conclusions: Cilostazol could alleviate hepatic fibrogenesis induced by $\mathrm{CCl}_{4}$ even at clinical doses. Our data indicate the possibility of a direct effect of cilostazol on HSC activation in vivo, which is pivotal for liver pathogenesis. Given its clinical availability and safety, it may be a novel therapeutic intervention for chronic liver diseases.

Key words: carbon tetrachloride; cilostazol; hepatic stellate cells; liver fibrosis; platelet derived growth factor; phosphodiesterase-3 inhibitor 


\section{Introduction}

Liver fibrosis, a precursor to cirrhosis, is a common consequence of almost all types of chronic liver injury, including viral, alcoholic, autoimmune, metabolic, and drug-induced liver diseases. ${ }^{1}$ Fibrosis results from excessive accumulation of extracellular matrix (ECM) components, such as collagen type I. Left untreated, fibrosis can progress to liver cirrhosis and ultimately lead to organ failure and death. The activation of hepatic stellate cells (HSCs) in response to liver injury is considered to be an essential event underlying hepatic fibrogenesis. ${ }^{2-4}$ The activation of HSCs refers to the transdifferentiation of quiescent HSCs into proliferative and contractile myofibroblast-like cells. These activated HSCs secrete excess ECM proteins and contribute to the development of hepatic fibrosis. Several types of growth factors, cytokines, chemokines, and their cognate receptors are associated with HSC activation. Among these, transforming growth factor beta (TGF- $\beta$ ) and platelet derived growth factor (PDGF) are probably the most important. ${ }^{5-7}$ HSCs play a key role in liver fibrosis, and so the restraint of HSC activation may attenuate liver fibrosis. Thus, numerous studies have attempted to suppress the activation of HSCs in order to develop new treatment strategies for hepatic fibrosis. ${ }^{8-11}$ Cilostazol (OPC-13013 (6-[4-(1-cyclohexyl-1H-tetrazol-5-yl)butoxy]-3,4-dihydro-2(1H)-quinolinone) is a 
synthetic vasodilator and an antiplatelet agent. It was approved in 1988 in Japan for the treatment of symptoms related to occlusive peripheral arterial disease (Pletaal ${ }^{\circledR}$ ) and subsequently in 1999 in the U.S. and 2001 in the U.K. $\left(\right.$ Pletal $^{\circledR}$ ) for the treatment of intermittent claudication symptoms. ${ }^{12-14}$ Over the past 20 years, it has widely been used as a potent inhibitor of platelet aggregation and thrombosis. ${ }^{15-18}$ Also, it has been shown to inhibit PDGF secretion in vitro. ${ }^{19}$ The antiplatelet activity of cilostazol is attributed to its inhibition of cyclic adenosine monophosphate (cAMP) phosphodiesterase (PDE). Recent studies have identified 11 different families of PDE. Of these, cilostazol selectively inhibits PDE3, which is predominantly expressed in platelets, vascular smooth muscle cells, cardiac myocytes, and hepatic cells. ${ }^{20,21}$ Recently, increased intracellular cAMP has been shown to inhibit HSC activation ${ }^{22-25}$ though little is known about the effect of cilostazol on liver fibrosis. Furthermore, cilostazol was shown to have an antifibrotic potential in experimental non-alcoholic fatty liver disease. ${ }^{26}$ However, the precise mechanisms of its antifibrotic effect and the efficacy in a different experimental model are elusive. This study was designed to investigate the effect of cilostazol on $\mathrm{CCl}_{4}$-induced hepatic fibrogenesis in mice and to clarify its mechanism of action by pathological examination and analysis of the primary cells derived from the mice. 


\section{Methods}

Animals. Male C57BL/6J mice aged four weeks were purchased from Japan SLC Inc.

(Shizuoka, Japan). After an acclimation period of seven days, the mice were randomly assigned to five treatment groups ( $n=10$ per group) in a single-blinded fashion (Fig. 1 ). Mice were maintained on standard chow and allowed free access to food and water. The protocol for animal handling was reviewed and approved by the Animal Care and Use Committee of Kyoto University.

Mouse model of liver fibrosis. Two weeks after assignment into treatment groups, mice were treated with carbon tetrachloride $\left(\mathrm{CCl}_{4} ; 2 \mu \mathrm{l} / \mathrm{g}\right.$ body weight diluted 1:4 in corn oil) by intraperitoneal injection twice a week for six weeks. Mice were collected four days after the last injection.

Drugs and drug treatment. The antiplatelet drug cilostazol was a gift from Otsuka Pharma Co., Ltd. (Tokushima, Japan). Clopidogrel was purchased from Sanofi-Aventis Co., Ltd. (Tokyo, Japan). Each drug was administered in standard pellet food (Oriental Bio Service, Kyoto, Japan) containing cilostazol (0.1\% w/w), cilostazol (0.3\% w/w), or clopidogrel $(0.125 \% \mathrm{w} / \mathrm{w})$. Oral treatment with cilostazol at $0.1 \%$ and $0.3 \% \mathrm{w} / \mathrm{w}$, and clopidogrel at $0.125 \% \mathrm{w} / \mathrm{w}$ of chow is equivalent to clinically used doses. ${ }^{27-29}$ The alternative antiplatelet drug clopidogrel was used as a control. To raise and stabilize the 
plasma concentration of drugs, we set the pretreatment of the drugs for two weeks. All animals were closely observed for two weeks after the dietary change, then received $\mathrm{CCl}_{4}$ injections for six weeks. Food intake, body-weight change were monitored throughout the whole experimental period for eight weeks. Blood samples were collected from inferior vena cava of the mice, and liver weights were recorded at sacrifice.

Histological examination and immunohistochemistry. For histological evaluation, the right lobe of the liver of each mouse was collected at sacrifice and fixed in $4 \%$ paraformaldehyde (PFA). In order to assess fibrosis, paraffin-embedded sections were stained with picrosirius red (Sigma, St. Louis, MO, USA). ${ }^{30}$ Expression of alpha smooth muscle actin ( $\alpha$-SMA) and F4/80 were determined in paraffin-embedded sections by immunohistochemistry as described previously ${ }^{31}$ using a monoclonal antimouse $\alpha$-SMA antibody (1:300, clone: 1A4; Dako, Glostrup, Denmark) or antimouse F4/80 antibody (1:100, clone: BM8, eBioscience, CA, USA), respectively.

Sirius red-positive areas, $\alpha$-SMA-positive areas and F4/80-positive areas were quantified from ten random $100 \times$ fields from each animal ( $n=10$ per treatment group) using image processing software (BZ analyzer; Keyence, Osaka, Japan). Data are presented as percentage area positively stained for sirius red, $\alpha$-SMA or F4/80 .

Measurement of hepatic collagen content. For measurement of liver fibrosis, the 
specific amino acid of collagen type I, hydroxyproline, was quantified in liver tissue.

Hepatic hydroxyproline content was measured as previously described. ${ }^{32}$ In brief, liver tissue was homogenized in $900 \mu \mathrm{l}$ of ice-cold distilled water. Subsequently, $125 \mu \mathrm{l}$ of $50 \%$ trichloroacetic acid was added, and the homogenates were incubated on ice for 20 min. Precipitated pellets were hydrolyzed for $18 \mathrm{~h}$ at $110^{\circ} \mathrm{C}$ in $6 \mathrm{~N} \mathrm{HCl}$. After hydrolysis, the samples were filtered and neutralized with $10 \mathrm{~N} \mathrm{NaOH}$, and hydrolysates were oxidized with chloramine-T (Sigma) for $25 \mathrm{~min}$ at room temperature. The reaction mixture was then incubated in Ehrlich's-perchloric acid solution at $65^{\circ} \mathrm{C}$ for 20 min and then cooled to room temperature. Sample absorbance was measured at $560 \mathrm{~nm}$ in duplicate. Purified hydroxyproline (Sigma) was used as a standard. Hydroxyproline content was expressed as nanograms of hydroxyproline per gram of liver.

Western blotting. For analysis of $\alpha$-SMA protein expression, western blotting was performed from whole liver lysates (20 $\mu \mathrm{g} / \mathrm{lane})$ using standard techniques. Immunoblotting was performed using a polyclonal antigoat GAPDH antibody (1:200; \#sc-20357; Santa Cruz, CA, USA) as an internal control, a polyclonal antirabbit $\alpha$-SMA antibody (1:200; \#ab-5694; Abcam, Cambridge, UK) and horseradish peroxidase-conjugated secondary antibodies (Santa Cruz) as described in the manufacturer's protocol. ${ }^{33}$ Antibody staining was visualized with an enhanced 
chemiluminescence system (GE Healthcare Biosciences, Little Chalfont, UK) using Lumino-image analyzer (LAS-3000 mini; Fujifilm, Tokyo, Japan). Band density was quantified from digital images using Image $\mathrm{J}$ software.

Isolation and culture of hepatic cells. Primary HSCs, Kupffer cells and Hepatocytes were isolated from mouse livers as described previously. ${ }^{34,} 35,{ }^{36}$ In brief, HSCs and Kupffer cells were isolated from mice by two-step collagenase-pronase perfusion followed by three-layer discontinuous density gradient centrifugation with $8.2 \%$ (wt/vol) and 14.5\% (wt/vol) Nycodenz (Accurate Chemical and Scientific Corporation, NY, USA) to obtain HSC and Kupffer cell fractions. HSCs were collected between the 0 and 8.2\% (wt/vol) layer. Kupffer cells were collected between the 8.2 and $14.5 \%$ (wt/vol) layer and were purified by differential plating. HSCs and Kupffer cells were cultured in Dulbecco’s modified Eagle’s medium (DMEM; Sigma) supplemented with $10 \%$ fetal bovine serum (FBS) and antibiotics. HSCs were cultured in William's Medium E supplemented with $10 \%$ fetal bovine serum (FBS) and antibiotics on the collagen coated dish. Hepatic cells were cultured in a $\mathrm{CO}_{2}$ incubator at $37^{\circ} \mathrm{C}$.

Cilostazol treatment. Cilostazol was dissolved in dimethylsulfoxide (DMSO) and diluted in DMEM supplemented with 10\% FBS and antibiotics. Complete medium containing final concentration of $0 \mu \mathrm{M}$ (control), $5 \mu \mathrm{M}$ and $15 \mu \mathrm{M}$ cilostazol was added 
to cultures one day after isolation.

Measurement of Intracellular cAMP. The intracellular cAMP level was measured as described previously ${ }^{37}$ using the cAMP-Glo max assay kit (Promega, USA). Briefly, $1 \mathrm{x}$ $10^{4}$ cells were seeded in a 96-well-plate well with or without cilostazol in culture medium containing $10 \%$ FBS and incubated in $37^{\circ} \mathrm{C}$ for $24 \mathrm{~h}$. The cAMP detecting solution was added to each well and incubated at room temperature for $20 \mathrm{~min}$. The Kinase-Glo reagent was added to each well. The plate was shaken for one min at room temperature and incubated at room temperature for ten min. Finally, luminescent signal was measured by a plate reader (Arvo; Perkin-Elmer,MA, USA).

Time-lapse recording and cell counting. For the observation of morphological changes, HSCs were placed in a Lab-Tek plastic 4-well chamber slide (Nunc, Inc., Naperville, IL) and maintained at $37^{\circ} \mathrm{C}$ in $10 \% \mathrm{CO}_{2}$. Time-lapse images were taken using an inverted microscope (BZ9000; Keyence, Osaka, Japan) over six days following cilostazol treatment. Cells were counted in four random 100× fields on each chamber using the image processing software, BZ analyzer.

Cytochemical analysis. Primary HSCs in each chamber were fixed in 10\% formalin/PBS for 10 min, blocked with Dako Protein Block (\#X0909; Dako, Glostrup, Denmark) for 1 h, incubated overnight with a polyclonal antimouse $\alpha$-SMA antibody (1:200; \#A2524, 
Sigma) in a blocking solution, washed with PBS, and incubated with Alexa Flour 594 goat antimouse IgG (1:600; \#A-11005; Invitrogen, CA, USA) secondary antibody and 4',6-diamidino-2-phenylindole (DAPI) nuclear stain for $1 \mathrm{~h}$. Finally, HSCs were washed and observed with an inverted fluorescence microscope, BZ9000.

Reverse-transcriptase quantitative polymerase chain reaction (RT-qPCR). For gene expression analysis, total RNA was extracted from HSCs or Kupffer cells using TRIZOL reagent (Invitrogen) according to the manufacturer's protocol. DNase treated RNA was reverse-transcribed using the Omniscript RT Kit (Qiagen, Hilden, Germany) according to the manufacturer's protocol. RT-qPCR was performed for 55 cycles of $15 \mathrm{~s}$ at $95^{\circ} \mathrm{C}$ and $60 \mathrm{~s}$ at $60^{\circ} \mathrm{C}$ using SYBR Green I Kits for the LightCycler 480 instrument (Roche Diagnostics, Mannheim, Germany). The relative abundance of target genes was calculated using a standard curve normalized to $\alpha$-tublin or 18S. Probes and primers for a-SMA (NM_007392), collagen a1(I) (NM_007742), PDGF-BB (NM_011057), PDGFR- $\beta \quad$ (NM_008809), $\quad$ TGF- $\beta 1 \quad$ (NM_011577), $\quad$ TGF- $\beta$ R1 (NM_009370), TNF- $\alpha$ (NM_013693), $\quad$ IL1- $\beta \quad$ (NM_008361), $\quad$ MCP1 $\quad$ (NM_011333), $\quad$ F4/80 (NM_010130), 18S (NR_003278) and $\alpha$-tublin (NM_011653) were designed by and purchased from ABI.

Statistical analysis. Results are reported as mean $\pm 95 \%$ confidence intervals (C.I.s). 
Statical comparisons were made using Student t test or two-way or one-way analysis of variance (ANOVA) followed by Bonferroni post-hoc test. $p<0.05$ was considered to be significant.

\section{Results}

\section{Cilostazol alleviated fibrous change of the liver.}

In order to validate the antifibrotic efficacy of cilostazol, we utilized a widely used experimental mouse model of liver fibrosis induced by $\mathrm{CCl}_{4}$ injections (twice a week for six weeks; Fig. 1). Based on the pharmacokinetic data of the plasma concentration of the drugs, $0.1 \%$ and $0.3 \%$ cilostazol and $0.125 \%$ clopidogrel were used as clinically equivalent doses. Collagen deposition, a marker for liver fibrosis, was assessed by sirius red staining (Fig. 2A). Sirius red staining of the liver was significantly less in the $0.1 \%$ and $0.3 \%$ cilostazol-administrated groups (2.49\%; 95\% C.I. 2.18-2.80; and 2.31\%; C.I. 2.10-2.52) compared with the control group (3.17\%; C.I. 2.70-3.65; $p<0.05$ and $p<$ 0.001, respectively), but clopidogrel had no effect (Figs. 2A, B). This was reflected by hydroxyproline content, which was significantly reduced in the $0.3 \%$ cilostazol-administrated group (317 ng/mg liver; C.I. 289-346) compared with the control group (371 ng/mg liver; C.I. 344-398; $p<0.001$; Fig. 2C). Thus, oral administration of cilostazol reduces hepatic fibrogenesis at clinical doses. During the 
eight-week experimental duration, no significant difference in body-weight change or peripheral platelet count was observed among treatment groups (Figs. 3A, B), indicating minimal toxicity of the drugs. Moreover, there was no apparent difference in $\mathrm{CCl}_{4}$-induced hepatocyte damage among the groups, as assessed by peripheral blood AST and ALT levels (Figs. 3C, D) and HE staining (Fig. 3E). We also observed no morphological change in cultured primary hepatocytes supplemented with cilostazol (Fig. 3F).

\section{Cilostazol attenuated the activation of HSCs in the liver.}

Chronic liver injury can lead to unrestrained HSC activation, resulting in excessive production of extracellular matrices and hepatic fibrosis. Thus, we assessed the activation status of HSCs in the liver, by immunohistochemical staining of $\alpha$-SMA, a marker of HSC activation (Fig. 4A). Similar to the sirius red staining, the $\alpha$-SMA positive area in the livers of $0.1 \%$ (4.16\%; C.I. 3.17-5.15) and $0.3 \%$ (2.61\%; C.I. 2.17-3.05) cilostazol-administrated groups was clearly reduced in a dose-dependent manner compared with the control group (7.13\%; C.I. 4.10-10.2; $p<0.05$ and $p<0.001$, respectively; Fig. 4B) and clopidogrel-administrated animals (original magnification $100 \times)$. This was also reflected by immunoblotting experiments in which $\alpha$-SMA protein expression was significantly reduced in the $0.3 \%$ cilostazol-administrated group $(0.44 \%$; 
C.I. 0.29-0.60) compared with the control group (1.14\%; C.I. 0.55-1.72; $p<0.05$; Fig.

4C). These results indicate that cilostazol has potent activity to attenuate the activation of HSCs in the liver through unkown mechanisms.

\section{Cilostazol directly and effectively inhibits the activation of HSCs but not of Kupffer cells}

To reveal the possible mechanisms behind these in vivo observations, we performed in vitro studies in primary cultures of HSCs. Generally, isolated HSCs undergo autonomous activation in culture, and the activation is associated with a depletion of retinoid droplets, morphological change, cell proliferation, and expression of several activation markers such as $\alpha$-SMA and collagen $\alpha 1$ (I). During six days of culture, control HSCs gradually lost retinoid droplets and showed myofibroblast-like activated morphology, while cilostazol-supplemented HSCs maintained retinoid droplets and kept their morphology as quiescent (Fig. 5A). In addition, cilostazol suppressed HSC proliferation in a dose dependent manner, without showing cell toxicity (Fig. 5B).The expression of $\alpha$-SMA protein was dose-dependently suppressed in the presence of cilostazol (Fig. 5C). Because Kupffer cells were also shown to be implicated in liver fibrosis as well as HSCs, $\underline{11}, \underline{38-40}$ we examined the effect of cilostazol on Kupffer-cell activation in vivo and in vitro. The pathological examination revealed a weak tendency for the decrease in F4/80-positive (Kupffer cell) area in the liver of 
cilostazol-administrated mice, however, we could not detect significant changes in our experimental setting (Figs. 5D and E). In fact, cilostazol did not affect the messenger RNA (mRNA) expression of F4/80 in isolated Kupffer cells (Fig. 5F), suggesting the minimal effect of cilostazol in vivo might be simply explained by the secondary effect of the resolution of fibrosis. Likewise, cilostazol exhibits an insignificant effect on the Kupffer-cell production of TNF- $\alpha$, IL-1 $\beta$, MCP1 and TGF- $\beta 1$ (Fig. 5F). These data together propose the notion that the in vivo therapeutic efficacy of cilostazol is mediated, at least in part, via its direct effects on HSCs. If then, why did HSCs respond well to cilostazol? One possible explanation is that HSCs are more sensitive to cilostazol than other cell-types (e.g. Kupffer cells). Actually, the cilostazol-induced cAMP accumulation, which is an indicator for cilostazol inhibition of PDE3 enzyme, is only significantly higher in HSCs supplemented with cilostazol (2.283; C.I. 1.45-3.12; $p<0.01$ ) but not in Kupffer cells (1.363; C.I. 0.4374-2.289; Fig. 5G), (original magnification 100x).

\section{Cilostazol suppressed PDGF receptor expression in HSCs.}

To further delineate the effect of cilostazol on the activation of HSCs, we characterized the cilostazol-affected gene expression profiles during the activation phase of HSCs. Firstly, to confirm the direct effects of cilostazol on the gene activation mechanism of HSCs, we examined the $\alpha$-SMA and collagen $\alpha 1$ (I) gene induction. As suggested by 
the previous data (Figs. 2, 4 and 5), mRNA induction of $\alpha$-SMA was lower in cells supplemented with $5 \mu \mathrm{M}$ cilostazol (0.555; C.I. 0.085-1.024) and $15 \mu \mathrm{M}$ cilostazol (0.221; C.I. 0.086-0.356) when compared with the control (2.53; C.I. 1.01-4.05; $p<$ 0.01; Fig. 6A). Similarly, collagen $\alpha 1$ (I) mRNA expression was lower in cells supplemented with $5 \mu \mathrm{M}$ cilostazol (0.411; C.I. 0.010-0.833) and $15 \mu \mathrm{M}$ cilostazol (0.059; C.I. 0.042-0.159) as compared with the control cells (2.20; C.I. 0.31-4.08; $p<$ 0.01; Fig. 6B). Then, to gain further mechanistic insights in the action of cilostazol on HSCs, the mRNA expression of PDGF-B, PDGFR- $\beta$ and TGF- $\beta$ R1, an important cytokine and cytokine receptors for HSC activation, was determined. Expression of PDGF-B, one of the most important mitogens for HSCs, was unaffected by cilostazol treatment (Fig. 6C), but PDGFR- $\beta$ mRNA expression in the $5 \mu \mathrm{M}$ cilostazol-supplemented cells $\quad(0.282 ; \quad$ C.I. $0.104-0.460)$ and $15 \mu \mathrm{M}$ cilostazol-supplemented cells (0.336; C.I. 0.036-0.636) was significantly decreased compared with control cells (0.749; C.I. 0.290-1.210; $p<0.001$; Fig. 6D). On the other hand, TGF- $\beta$ R1 mRNA expression was not affected by cilostazol treatment (Fig. 6E). These results indicate the possibility that cilostazol attenuates the activation-induced proliferation of HSCs through abrogation of the PDGF-autocrine signaling by limiting the receptor (PDGFR- $\beta$ ) signaling regardless of the ligand (PDGF) availability. 


\section{Discussion}

The oral administration of cilostazol effectively prevents the development of $\mathrm{CCl}_{4}$-induced liver fibrosis in mice. In agreement with the previous study, cilostazol was not toxic to the HSCs as indicated by the morphology and the proliferation of the cells (Figs. 5A and B). ${ }^{25}$ It is noteworthy that unlike many other candidate medications, cilostazol is already widely used as an antiplatelet agent in clinical practice with proven long-term safety. For this reason, cilostazol holds potential to become an antifibrotic agent for chronic liver diseases in humans.

In the present study, we employed clopidogrel as an alternative antiplatelet agent for the comparison. Although both cilostazol and clopidogrel showed minimal side effects (Figs. 3A-F), only cilostazol attenuated liver fibrosis (Figs. 2 and 4), suggesting that cilostazol may have distinct antifibrotic mechanisms apart from its antiplatelet action. This notion is consistent with the results of the present in vitro study in which the treatment of primary HSCs with cilostazol attenuated the HSC proliferation (Fig. 5B) and the expression of $\alpha$-SMA and collagen $\alpha 1$ (I) (Figs. 5C and 6), indicating the direct effect of cilostazol on HSCs.

As reported, ${ }^{6,}$ 39, 41 PDGFR- $\beta$ was absent in quiescent HSCs, but was upregulated in an early stage of liver injury. Activating factors from autocrine or paracrine sources such as 
TGF- $\beta$ stimulate the transcriptional induction of PDGFR- $\beta$ in quiescent HSCs, thereby rendering them responsive to PDGF-B chain molecules. Among several activating pathways, the autocrine-loop exerted by PDGF-PDGF receptor signaling is regarded as one of the most potent mitogenic pathways for HSCs. ${ }^{42}$ Although PDGF itself seemed unaffected in our study, our quantitative analyses showed cilostazol significantly suppressed PDGFR- $\beta$ in HSCs (Figs. 6C and D). Because, the PDGF-PDGF receptor signaling not only promotes myofibroblast proliferation but also participates in other fibrogenic actions including stimulation of collagen production and promotion of cell adhesion, it has been speculated that the activated PDGF-PDGF receptor signaling pathway might be a candidate target for antifibrotic therapy in liver diseases. ${ }^{43}$ Actually, focusing on PDGFR, recent studies showed attenuation of hepatic fibrosis by using a PDGFR tyrosine kinase inhibitor. ${ }^{44-46}$ In the same sense, a blockade of the autocrine-loop of PDGF-PDGF receptor signaling by cilostazol may also have the multiple benefits for preventing the development of hepatic fibrosis.

Cilostazol is a selective inhibitor of PDE3 and the PDE3 inhibition in platelets exhibits antithrombotic effects by avoiding platelet aggregation. Recently, increased intracellular cAMP levels and activation of PKA was reported to reduce the PDGF-stimulated cellular proliferation. ${ }^{47,48}$ Interestingly, cilostazol has been shown to be effective against 
NAFLD development through the activation of cAMP/PKA signaling pathway in vivo. ${ }^{26}$

Although the exact mechanism remains to be seen, there may be a link between PDGF receptor downregulation and cAMP/PKA signaling in HSCs.

In conclusion, orally bioavailable cilostazol attenuates HSC activation at clinically equivalent doses maybe through the suppression of PDGF-R expression in HSCs, and thereby alleviates hepatic fibrogenesis. Further studies have promise in offering future intervention strategy against liver diseases.

Competing interest: Drs Hata and Uemoto report receiving a grant from Otsuka Pharma Co., Ltd. Dr. Asagiri reports receiving a grant from the AK Project (between Astellas Pharma and Kyoto University). However, the study was designed, conducted, analyzed, and reported independently of the funding agencies and pharmaceutical companies, although cilostazol was supplied by Otsuka Pharmaceutical Co. Ltd. No other potential conflict of interest relevant to this article was reported.

Acknoledgements: We are grateful for technical assistance provided by the Central Laboratory of Osaka City University Medical School. We also thank Kimie Takafuji (Hamanaka), Eri Hikawa, Tadashi Mizutani, Kenta Aohara, Kazushi Yamasato and Marika Horiuchi. This work was supported in part by a Grant-in-Aid for Young 
Scientists (M.A.) and a Grant-in-Aid for Challenging Exploratory Research (M.A.) from Japan Society for the Promotion of Science; a grant from the Japanese Ministry of Health, Labour and Welfare (K.Iwaisako., K.Ikeda, M.A. and S.U.); and grants from Otsuka Pharma Co., Ltd. (K.H. and S.U.) and the Uehara Memorial Foundation (M.A.) 


\section{References}

1 Friedman SL. Mechanisms of hepatic fibrogenesis. Gastroenterology. 2008 May;134: 1655-69.

2 Gabele E, Brenner DA, Rippe RA. Liver fibrosis: signals leading to the amplification of the fibrogenic hepatic stellate cell. Front Biosci. 2003 Jan 1;8: d69-77.

3 Afdhal NH, Nunes D. Evaluation of liver fibrosis: a concise review. Am $J$ Gastroenterol. 2004 Jun;99: 1160-74.

4 Tsukada S, Parsons CJ, Rippe RA. Mechanisms of liver fibrosis. Clin Chim Acta. 2006 Feb;364: 33-60.

5 Inagaki Y, Higashiyama R, Higashi K. Novel anti-fibrotic modalities for liver fibrosis: molecular targeting and regenerative medicine in fibrosis therapy. $J$ Gastroenterol Hepatol. 2012 Mar;27 Suppl 2: 85-8.

6 Bonner JC. Regulation of PDGF and its receptors in fibrotic diseases. Cytokine Growth Factor Rev. 2004 Aug;15: 255-73.

7 Tsukamoto H. Cytokine regulation of hepatic stellate cells in liver fibrosis. Alcoholism, clinical and experimental research. 1999 May;23: 911-6.

8 Novobrantseva TI, Majeau GR, Amatucci A, et al. Attenuated liver fibrosis in the absence of B cells. J Clin Invest. 2005 Nov;115: 3072-82.

$9 \quad$ Bataller R, Brenner DA. Hepatic stellate cells as a target for the treatment of liver fibrosis. Semin Liver Dis. 2001 Aug;21: 437-51.

10 Friedman SL. Liver fibrosis -- from bench to bedside. J Hepatol. 2003;38 Suppl 1: S38-53.

11 Zhang D, Utsumi T, Huang HC, et al. Reticulon 4B (Nogo-B) is a novel regulator of hepatic fibrosis. Hepatology. 2011 Apr;53: 1306-15.

12 Kambayashi J, Liu YG, Sun B, Shakur Y, Yoshitake M, Czerwiec F. Cilostazol as a unique antithrombotic agent. Current Pharmaceutical Design. 2003;9: 2289-302.

13 Okuda Y, Mizutani M, Ikegami T, Ueno E, Yamashita K. Hemodynamic effects of cilostazol on peripheral artery in patients with diabetic neuropathy. Arzneimittelforschung. 1992 Apr;42: 540-2.

14 Wang S, Cone J, Fong M, Yoshitake M, Kambayashi J, Liu YG. Interplay between inhibition of adenosine uptake and phosphodiesterase type 3 on cardiac function by cilostazol, an agent to treat intermittent claudication. Journal of Cardiovascular Pharmacology. 2001 Nov;38: 775-83.

15 Kimura Y, Tani T, Kanbe T, Watanabe K. Effect of cilostazol on platelet aggregation and experimental thrombosis. Arzneimittelforschung. 1985;35: 1144-9.

16 Kohriyama T, Tanaka E, Katayama S, Yamamura Y, Nakamura S. [Antiplatelet 
therapy in patients with cerebral thrombosis at the chronic phase--assessment of its effect on coagulation and fibrinolytic parameters]. Rinsho Shinkeigaku. 1994 Aug;34: 771-6.

17 Liu Y, Cone J, Le SN, et al. Cilostazol and dipyridamole synergistically inhibit human platelet aggregation. J Cardiovasc Pharmacol. 2004 Aug;44: 266-73.

18 Liu Y, Shakur Y, Yoshitake M, Kambayashi Ji J. Cilostazol (pletal): a dual inhibitor of cyclic nucleotide phosphodiesterase type 3 and adenosine uptake. Cardiovasc Drug Rev. 2001 Winter;19: 369-86.

19 Mizutani M, Okuda Y, Yamashita K. Effect of cilostazol on the production of platelet-derived growth factor in cultured human vascular endothelial cells. Biochem Mol Med. 1996 Apr;57: 156-8.

20 Bender AT, Beavo JA. Cyclic nucleotide phosphodiesterases: molecular regulation to clinical use. Pharmacological reviews. 2006 Sep;58: 488-520.

21 Hayashi S, Morishita R, Matsushita H, et al. Cyclic AMP inhibited proliferation of human aortic vascular smooth muscle cells, accompanied by induction of p53 and p21. Hypertension. 2000 Jan;35: 237-43.

22 Kawada N, Kuroki T, Kobayashi K, Inoue M, Kaneda K. Inhibition of myofibroblastic transformation of cultured rat hepatic stellate cells by methylxanthines and dibutyryl cAMP. Dig Dis Sci. 1996 May;41: 1022-9.

23 Mallat A, Preaux AM, Serradeil-Le Gal C, et al. Growth inhibitory properties of endothelin-1 in activated human hepatic stellate cells: a cyclic adenosine monophosphate-mediated pathway. Inhibition of both extracellular signal-regulated kinase and c-Jun kinase and upregulation of endothelin B receptors. J Clin Invest. 1996 Dec 15;98: $2771-8$.

24 Houglum K, Lee KS, Chojkier M. Proliferation of hepatic stellate cells is inhibited by phosphorylation of CREB on serine 133. J Clin Invest. 1997 Mar 15;99: 1322-8.

25 Shimizu E, Kobayashi Y, Oki Y, Kawasaki T, Yoshimi T, Nakamura H. OPC-13013, a cyclic nucleotide phosphodiesterase type III, inhibitor, inhibits cell proliferation and transdifferentiation of cultured rat hepatic stellate cells. Life Sci. 1999;64: 2081-8.

26 Fujita K, Nozaki Y, Wada K, et al. Effectiveness of antiplatelet drugs against experimental non-alcoholic fatty liver disease. Gut. 2008 Nov;57: 1583-91.

27 Hase Y, Okamoto Y, Fujita Y, et al. Cilostazol, a phosphodiesterase inhibitor, prevents no-reflow and hemorrhage in mice with focal cerebral ischemia. Experimental neurology. 2012 Jan;233: 523-33.

28 Hasegawa SI, J., Tuji Y, Saitoh E. Assessment of Buccal Absorption of Cilostazol 100-mg Orally Disintegrated Tablets in Healthy Adult Male Subjects. Jpn Pharmacol Ther. 2009;37: 7.

29 Hasegawa SI, J., Tuji Y, Saitoh E. Bioequivalence Study of Cilostazol 100-mg 
Orally Disintegrated Tablets and Cilostazol 100-mg Conventional Tablets in Healthy Adult Male Subjects. Jpn Pharmacol Ther. 2009;37: 8.

30 Isayama F, Hines IN, Kremer M, et al. LPS signaling enhances hepatic fibrogenesis caused by experimental cholestasis in mice. Am J Physiol Gastrointest Liver Physiol. 2006 Jun;290: G1318-28.

31 Toda Y, Kono K, Abiru H, et al. Application of tyramide signal amplification system to immunohistochemistry: a potent method to localize antigens that are not detectable by ordinary method. Pathol Int. 1999 May;49: 479-83.

32 Seki E, De Minicis S, Osterreicher CH, et al. TLR4 enhances TGF-beta signaling and hepatic fibrosis. Nat Med. 2007 Nov;13: 1324-32.

33 Schnabl B, Kweon YO, Frederick JP, Wang XF, Rippe RA, Brenner DA. The role of Smad3 in mediating mouse hepatic stellate cell activation. Hepatology. 2001 Jul;34: 89-100. 34 Siegmund SV, Uchinami H, Osawa Y, Brenner DA, Schwabe RF. Anandamide induces necrosis in primary hepatic stellate cells. Hepatology. 2005 May;41: 1085-95.

35 Weiskirchen R, Gressner AM. Isolation and culture of hepatic stellate cells. Methods Mol Med. 2005;117: 99-113.

36 Friedman SL, Roll FJ. Isolation and culture of hepatic lipocytes, Kupffer cells, and sinusoidal endothelial cells by density gradient centrifugation with Stractan. Analytical biochemistry. 1987 Feb 15;161: 207-18.

37 Mou L, Xing Y, Kong Z, Zhou Y, Chen Z, Wang R. The N-terminal domain of human hemokinin-1 influences functional selectivity property for tachykinin receptor neurokinin-1. Biochemical pharmacology. 2011 Mar 1;81: 661-8.

38 Tomita K, Tamiya G, Ando S, et al. Tumour necrosis factor alpha signalling through activation of Kupfer cells plays an essential role in liver fibrosis of non-alcoholic steatohepatitis in mice. Gut. 2006 Mar;55: 415-24.

39 Friedman SL, Arthur MJ. Activation of cultured rat hepatic lipocytes by Kupffer cell conditioned medium. Direct enhancement of matrix synthesis and stimulation of cell proliferation via induction of platelet-derived growth factor receptors. J Clin Invest. 1989 Dec;84: 1780-5.

40 Tsukamoto H, Gaal K, French SW. Insights into the pathogenesis of alcoholic liver necrosis and fibrosis: status report. Hepatology. 1990 Sep;12: 599-608.

41 Wong L, Yamasaki G, Johnson RJ, Friedman SL. Induction of beta-platelet-derived growth factor receptor in rat hepatic lipocytes during cellular activation in vivo and in culture. J Clin Invest. 1994 Oct;94: 1563-9.

42 Borkham-Kamphorst E, van Roeyen CR, Ostendorf T, Floege J, Gressner AM, Weiskirchen R. Pro-fibrogenic potential of PDGF-D in liver fibrosis. J Hepatol. 2007 Jun;46: 1064-74. 
43 Melton AC, Yee HF. Hepatic stellate cell protrusions couple platelet-derived growth factor-BB to chemotaxis. Hepatology. 2007 Jun;45: 1446-53.

44 Yasuda Y, Shimizu M, Sakai H, et al. (-)-Epigallocatechin gallate prevents carbon tetrachloride-induced rat hepatic fibrosis by inhibiting the expression of the PDGFRbeta and IGF-1R. Chem Biol Interact. 2009 Dec 10;182: 159-64.

45 Gonzalo T, Beljaars L, van de Bovenkamp M, et al. Local inhibition of liver fibrosis by specific delivery of a platelet-derived growth factor kinase inhibitor to hepatic stellate cells. J Pharmacol Exp Ther. 2007 Jun;321: 856-65.

46 Yoshiji H, Noguchi R, Kuriyama S, et al. Imatinib mesylate (STI-571) attenuates liver fibrosis development in rats. Am J Physiol Gastrointest Liver Physiol. 2005 May;288: G907-13.

47 Graves LM, Bornfeldt KE, Raines EW, et al. Protein kinase A antagonizes platelet-derived growth factor-induced signaling by mitogen-activated protein kinase in human arterial smooth muscle cells. Proc Nat1 Acad Sci U S A. 1993 Nov 1;90: 10300-4.

48 Mallat A, Gallois C, Tao J, et al. Platelet-derived growth factor-BB and thrombin generate positive and negative signals for human hepatic stellate cell proliferation. Role of a prostaglandin/cyclic AMP pathway and cross-talk with endothelin receptors. J Biol Chem. 1998 Oct 16;273: 27300-5. 


\section{Figure Legends}

Figure 1. Experimental protocol. Male adult C57BL/6J mice were fed the pelleted food containing $0.1 \%$ or $0.3 \%$ cilostazol or $0.125 \%$ clopidogrel, or control diet. Liver fibrosis was induced by intraperitoneal injection of $\mathrm{CCl}_{4}$ twice a week for six weeks. Mice were sacrificed four days after the last injection. CLZ: cilostazol, CPG: clopidogrel, $\mathrm{CCl}_{4}$ : carbon tetrachloride. $(n=10)$ 
Figure 2. Cilostazol alleviated fibrous changes in the liver. (A) Sirius red staining of liver sections in each group. $\mathrm{CCl}_{4}$ treatment for six weeks remarkably increased fibrotic area. $\mathrm{CCl}_{4}$-treated livers in the control or clopidogrel-administrated group showed bridging fibrosis. Cilostazol decreased fibrotic area among $\mathrm{CCl}_{4}$-treated mice (original magnification 100×). (B) Quantification of liver fibrosis area stained by sirius red. $\mathrm{CCl}_{4}$-induced fibrous areas in the $0.1 \%$ or $0.3 \%$ cilostazol-administrated groups were significantly decreased compared with that in the control group. (C) Hydroxyproline assay was performed to measure total collagen content. Administration with $0.3 \%$ cilostazol reduced tissue hydroxyproline levels compared with control. The box plots present the median and $25^{\text {th }}-75^{\text {th }}$ percentiles. Upper and lower lines are the minimum and maximum values $(n=10)$. ${ }^{*} p<0.05$; $† p<0.001$ vs. $\mathrm{CCl}_{4}$-treated control. $\mathrm{CCl}_{4}$; carbon tetrachloride, CLZ; cilostazol, CPG; clopidogrel. 
Figure 3. Body-weight change, peripheral platelet counts, hepatocyte damage and AST/ALT did not differ among the $\mathrm{CCl}_{4}$-treated groups. (A) Body-weight change during the eight-week experimental duration. Mice without $\mathrm{CCl}_{4}$ treatment showed the highest gain, but no significant differences were observed among all groups. (B) Peripheral platelet counts at sacrifice were not different among $\mathrm{CCl}_{4}$-treated groups. (C, D) Serum AST and ALT levels at sacrifice were not different among $\mathrm{CCl}_{4}$-treated groups. (E) HE staining of liver sections from each group (original magnification 100×). No obvious differences of hepatocytes damage existed among $\mathrm{CCl}_{4}$-treated groups. (F) Morphology of hepatocyes supplemented with cilostazol for one day was viewed on a phase contrast microscope (original magnification 200×). The morphology was unaffected by cilostazol supplementation. On line plots, each plot represents the mean of measurements $(n=10)$. The box plots present median and $25^{\text {th }}-75^{\text {th }}$ percentiles. Upper and lower lines are the minimum and maximum values $(n=10)$. $\mathrm{CCl}_{4}$; carbon tetrachloride, CLZ; cilostazol, CPG; clopidogrel. 
Figure 4. Cilostazol attenuated the expression of $\alpha$-SMA protein in the liver. (A) $\alpha$-SMA immunostaining of liver sections in each group. Treatment with $\mathrm{CCl}_{4}$ for six weeks remarkably increased $\alpha$-SMA expression. Among $\mathrm{CCl}_{4}$-treated groups, livers of cilostazol-administrated group have reduced $\alpha$-SMA positive areas compared with that of control diet or clopidogrel-administrated group (original magnification 100×). (B) Quantification of $\alpha$-SMA positive area in each group. Cilostazol-administrated groups had significantly decreased $\alpha$-SMA positive areas compared with control diet and clopidogrel-administrated groups. (C) Measurement of $\alpha$-SMA protein in livers by immunoblotting. Administration with $0.3 \%$ cilostazol reduced $\alpha$-SMA levels in $\mathrm{CCl}_{4}$-treated mice. The box plots present median and $25^{\text {th }}-75^{\text {th }}$ percentiles. Upper and lower lines are the minimum and maximum values $(n=10) . \quad * p<0.05$; $\dagger p<0.001$ vs. $\mathrm{CCl}_{4}$-treated control diet group. $\alpha$-SMA; $\alpha$-smooth muscle actin, $\mathrm{CCl}_{4}$; carbon tetrachloride, CLZ; cilostazol, CPG; clopidogrel. 
Figure 5. Cilostazol suppressed proliferation and activation of HSCs, but didn't affect Kupffer cell activation. (A) Morphological changes of HSCs from zero to six days were viewed on a phase contrast microscope (original magnification 100×). HSCs supplemented with $15 \mu \mathrm{M}$ cilostazol resulted in visible short cytoplasmic dendritic processes and perinuclear vacuoles containing retinoids. (B) HSC proliferation was determined by direct count of the cell numbers. Cilostazol supplementation slowed the increase in cell numbers compared with control. (C) Immunofluorescent staining of $\alpha$-SMA (red) in HSCs at the second day in culture. (original magnification $100 \times$ ). The protein expression of $\alpha$-SMA was decreased in cilostazol-supplemented HSCs in a dose-dependent manner. (D) F4/80 immunostaining of liver sections in each group. (original magnification 200×). (E) Quantification of F4/80 positive area in each group. Cilostazol-administrated groups tended to decrease F4/80 positive areas compared with control, but no significant differences were observed among $\mathrm{CCl}_{4}$ treated-groups. (F) Expression of Kupffer cell marker (F4/80) and inflammation-related genes (TNF- $\alpha$, IL1- $\beta$, MCP1 and TGF $\beta 1$ ) in primary Kupffer cells at the second day in culture was not altered by cilostazol. (G) Accumulation of cAMP in primary cultured HSCs and Kupffer cells. Cilostazol supplementation significantly elevated cAMP level only in HSCs. The box plots present median and $25^{\text {th }}-75^{\text {th }}$ percentiles. Upper and lower lines are the 
minimum and maximum values $(n=4) .{ }^{*} p<0.05$; $\dagger p<0.001 ; \ddagger p<0.01$ vs. control group. HSC; hepatic stellate cell, CLZ; cilostazol, $\alpha$-SMA; $\alpha$-smooth muscle actin, DAPI; 4', 6-diamidino-2-phenylindole, $\mathrm{CCl}_{4}$; carbon tetrachloride, TNF- $\alpha$; tumor necrosis factor- $\alpha$, IL1- $\beta$; interleukin1- $\beta$, MCP1; monocyte chemotactic protein-1, TGF- $\beta 1$; transforming growth factor- $\beta 1$, cAMP; cyclic adenosine monophosphate. 


\section{Figure 6. Expression of genes associated with HSC activation was assessed by}

RT-qPCR. (A) $\alpha$-SMA, (B) collagen $\alpha 1$ (I) and (D) PDGFR- $\beta$ expression levels in HSCs supplemented with $5 \mu \mathrm{M}$ and $15 \mu \mathrm{M}$ cilostazol for two days were significantly suppressed compared with control $(* p<0.05$; $\ddagger p<0.01$; $\dagger p<0.001$ vs. control, respectively). The expression of (C) PDGF-B and (E) TGF- $\beta$ R1 had no difference between control and cilostazol-supplemented HSCs. The box plots present median and $25^{\text {th }}-75^{\text {th }}$ percentiles. Upper and lower lines are the minimum and maximum values $(n=$ 7). HSC; hepatic stellate cell, CLZ; cilostazol, $\alpha$-SMA; $\alpha$-smooth muscle actin, PDGF-B; platelet growth factor-B, PDGFR- $\beta$; platelet growth factor receptor- $\beta$, TGF- $\beta$ R1; transforming growth factor- $\beta$ receptor1. 
$\mathrm{CCl}_{4}(-)$ Control diet

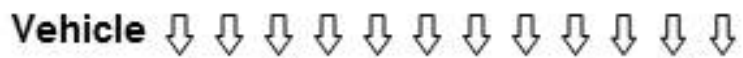

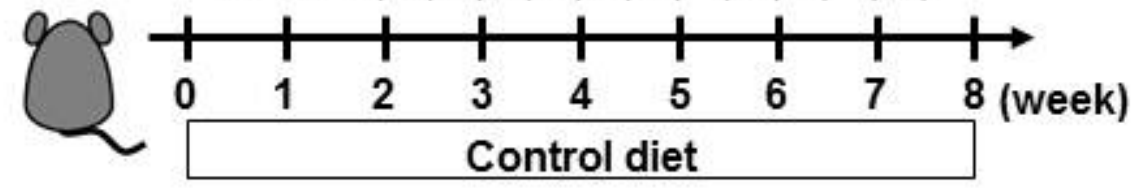

\section{$\mathrm{CCl}_{4}(+)$}

$0.1 \% \mathrm{CLZ}$

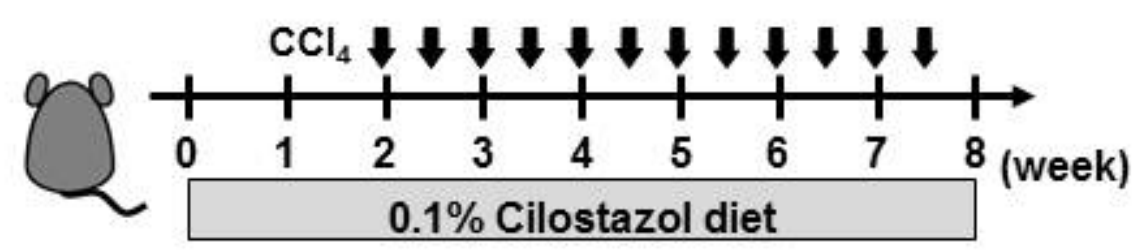

$\mathrm{CCl}_{4}(+)$

Control diet

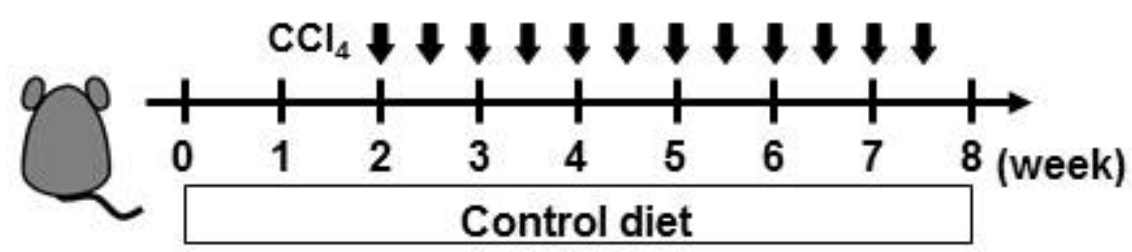

\author{
$\mathrm{CCl}_{4}(+)$ \\ $0.3 \% \mathrm{CLZ}$
}

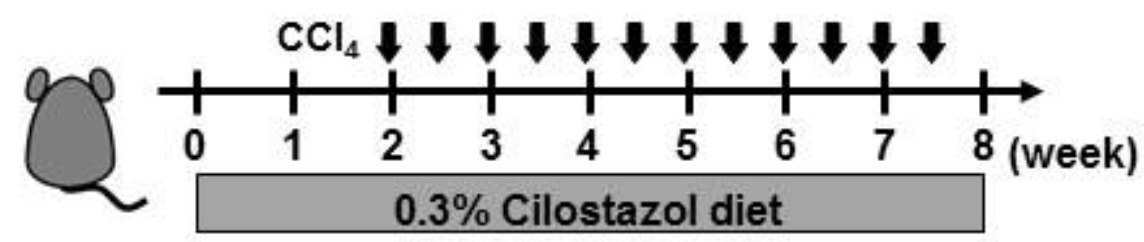

$\mathrm{CCl}_{4}(+)$

CPG

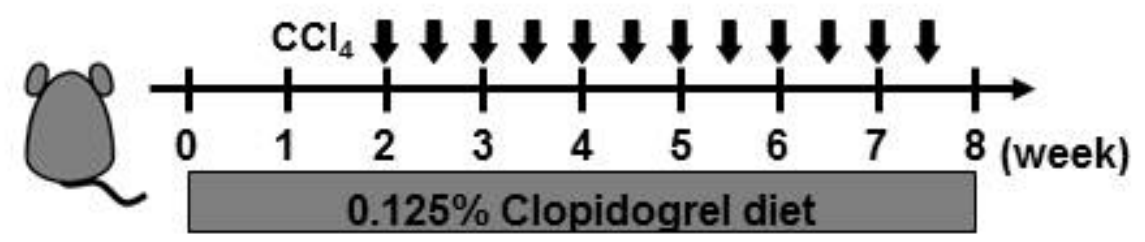

f. Vehicle; i.p.

1 $\mathrm{CCl}_{4} ; 0.5 \mu \mathrm{l} / \mathrm{g}-\mathrm{BW}$ i.p. 
A

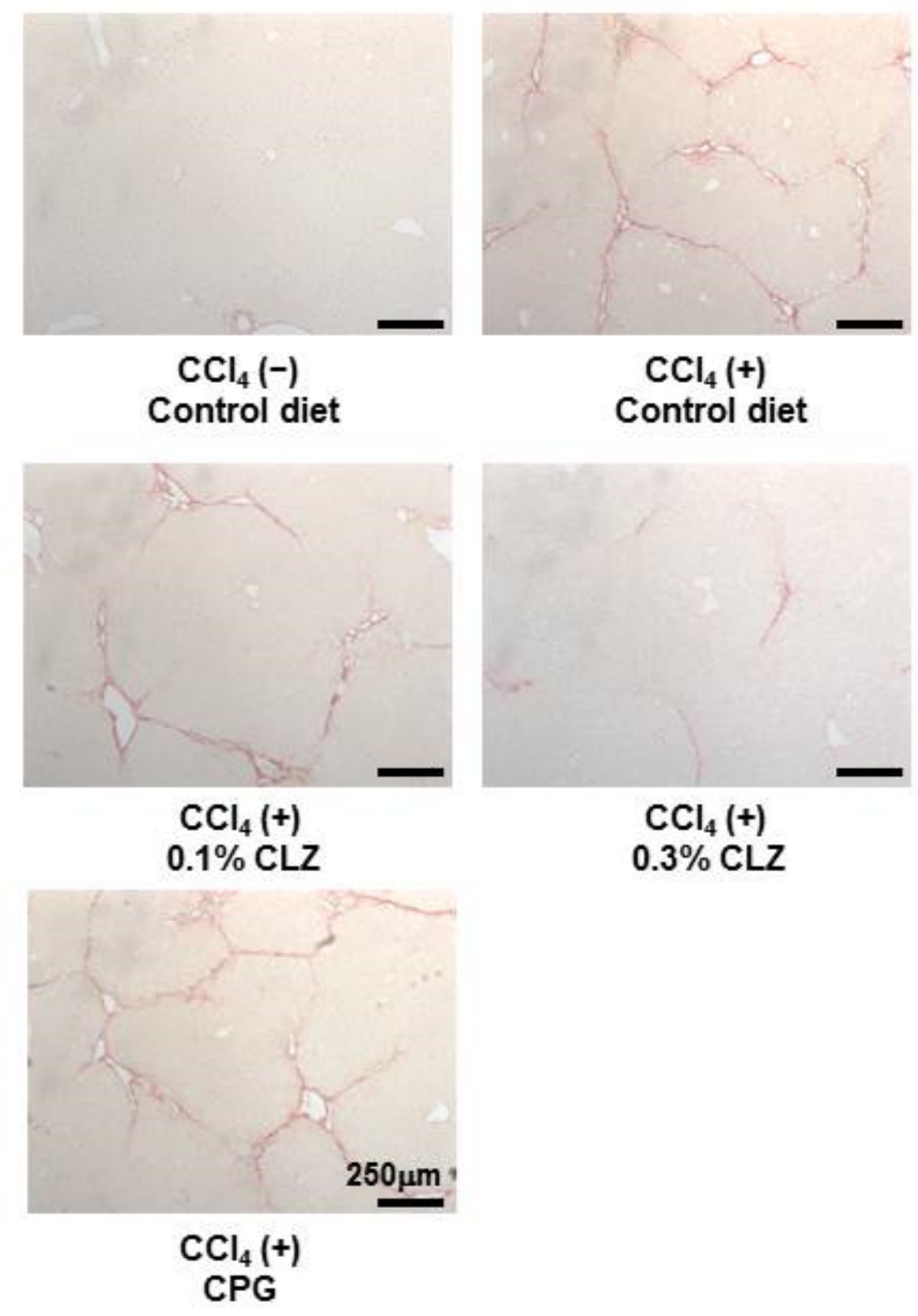

B
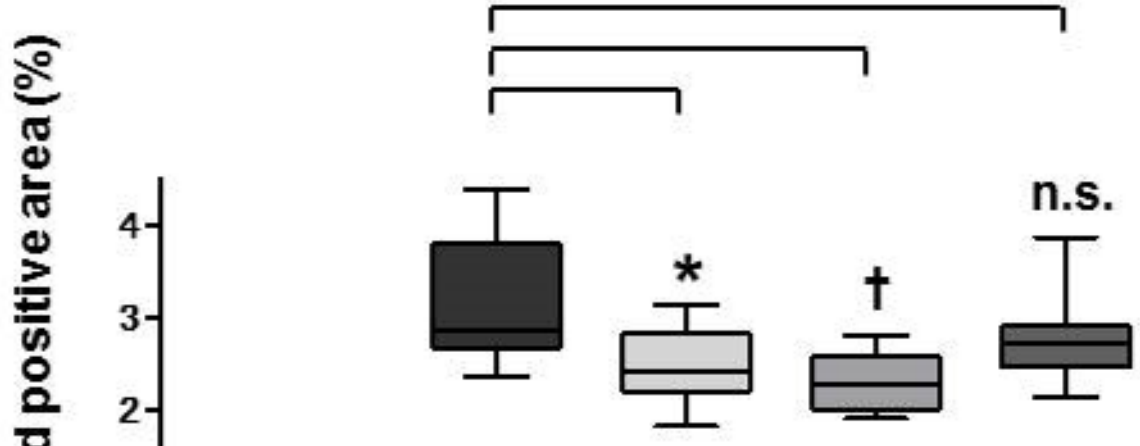

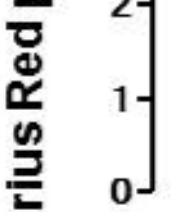

ऊ $\mathrm{CCl}_{4}$

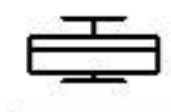
CLZ CPG

C

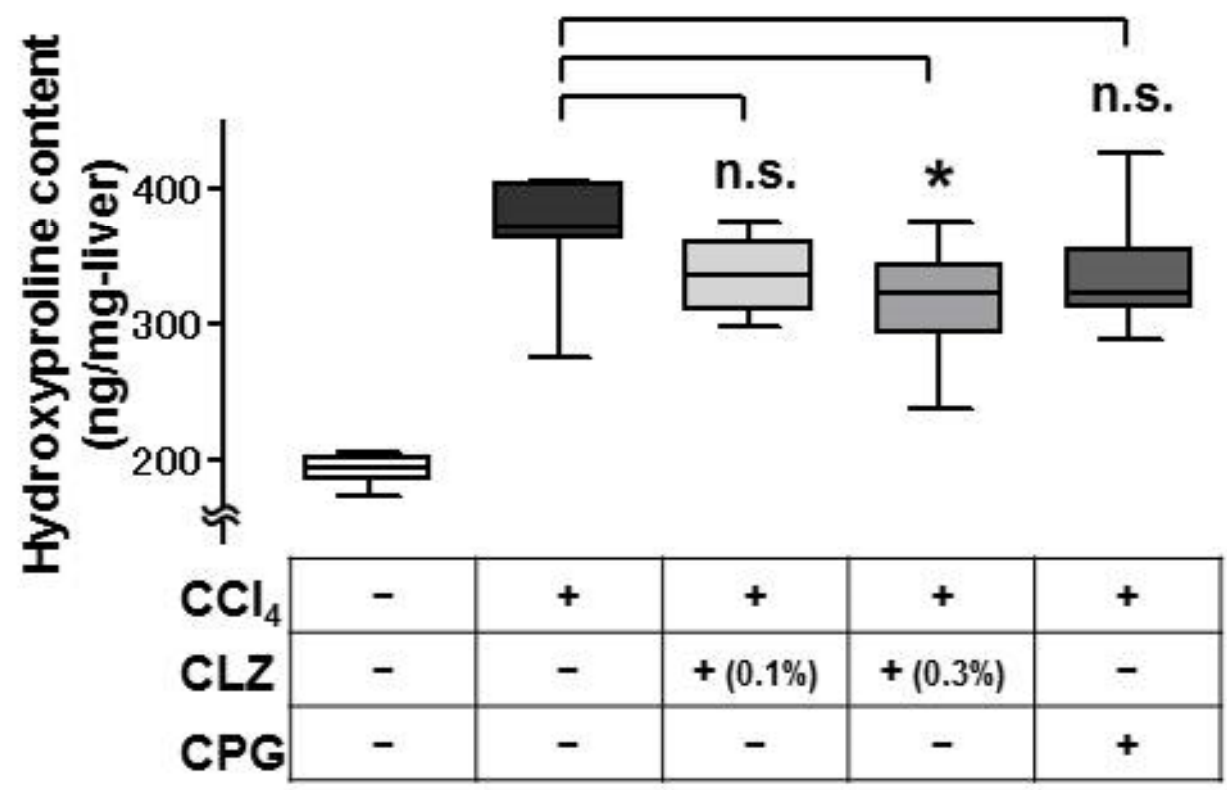

Figure 2 
A
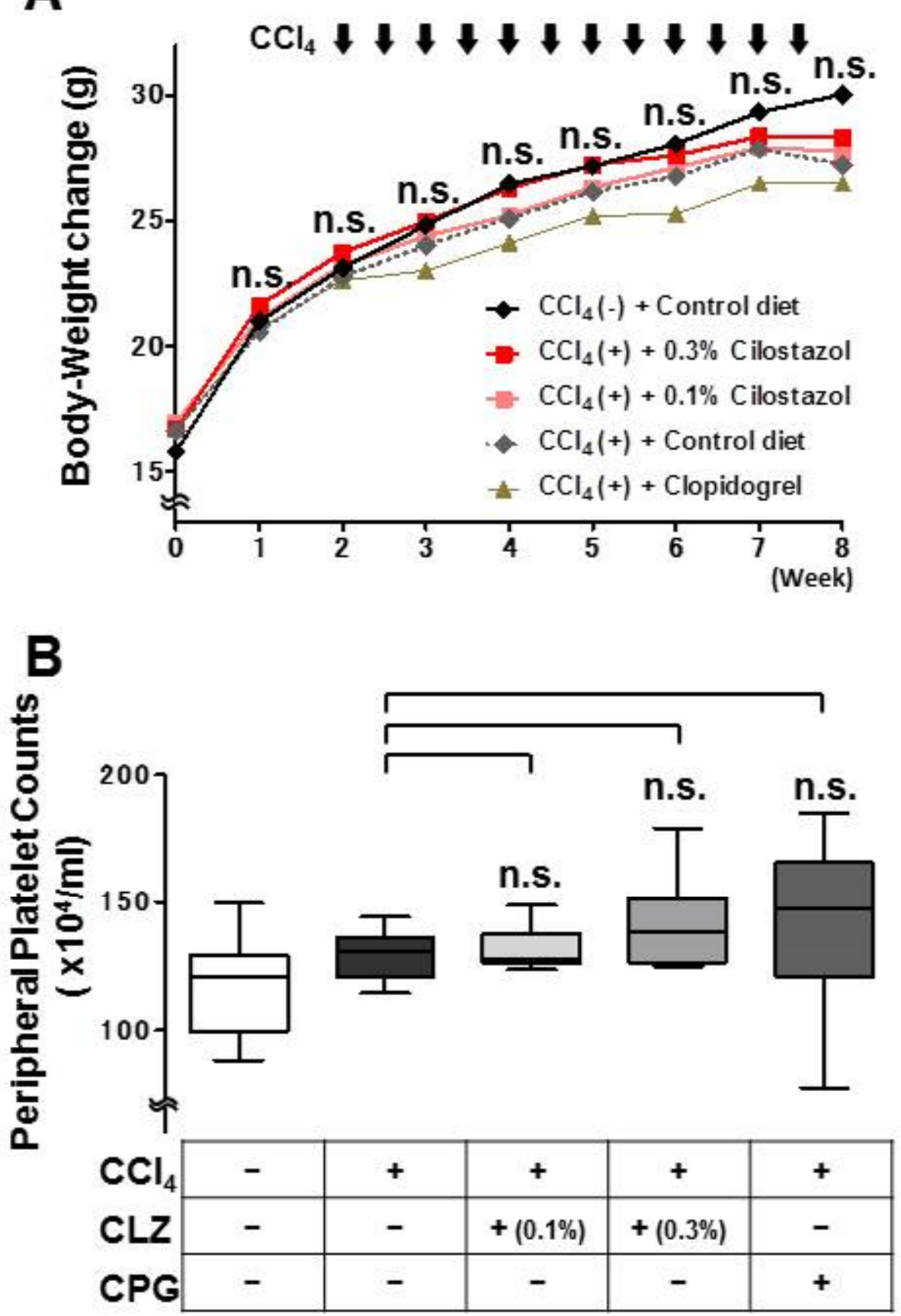

C

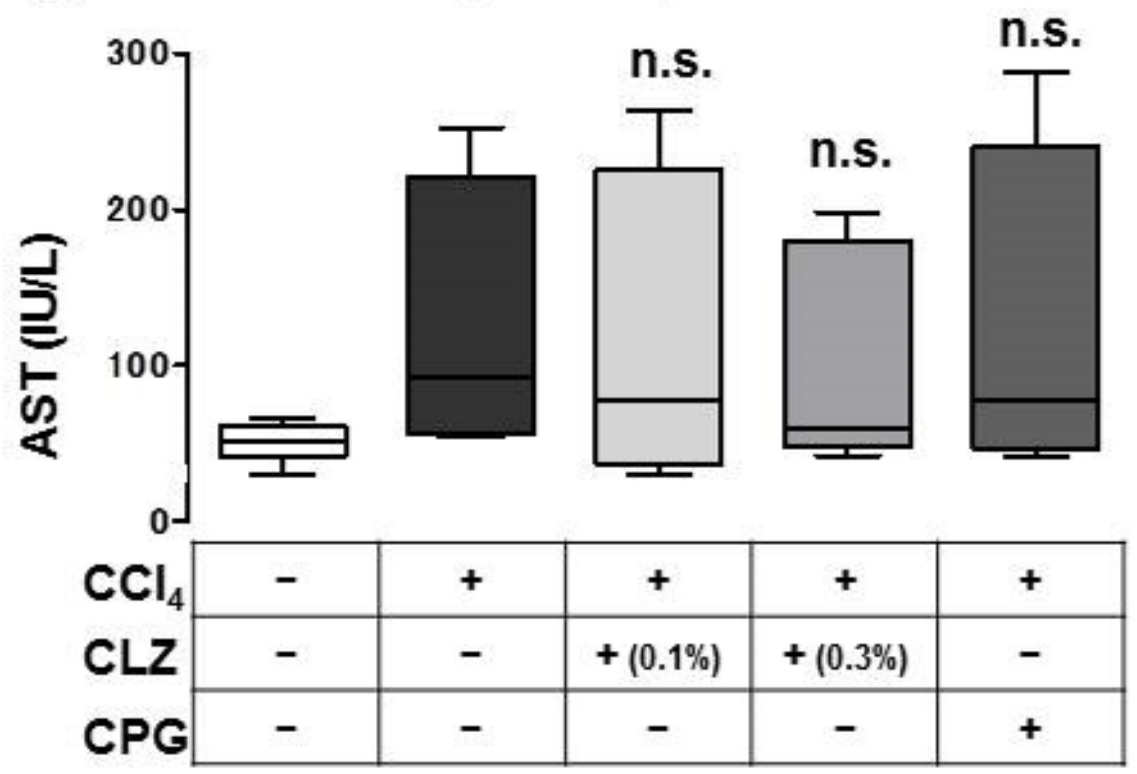

D

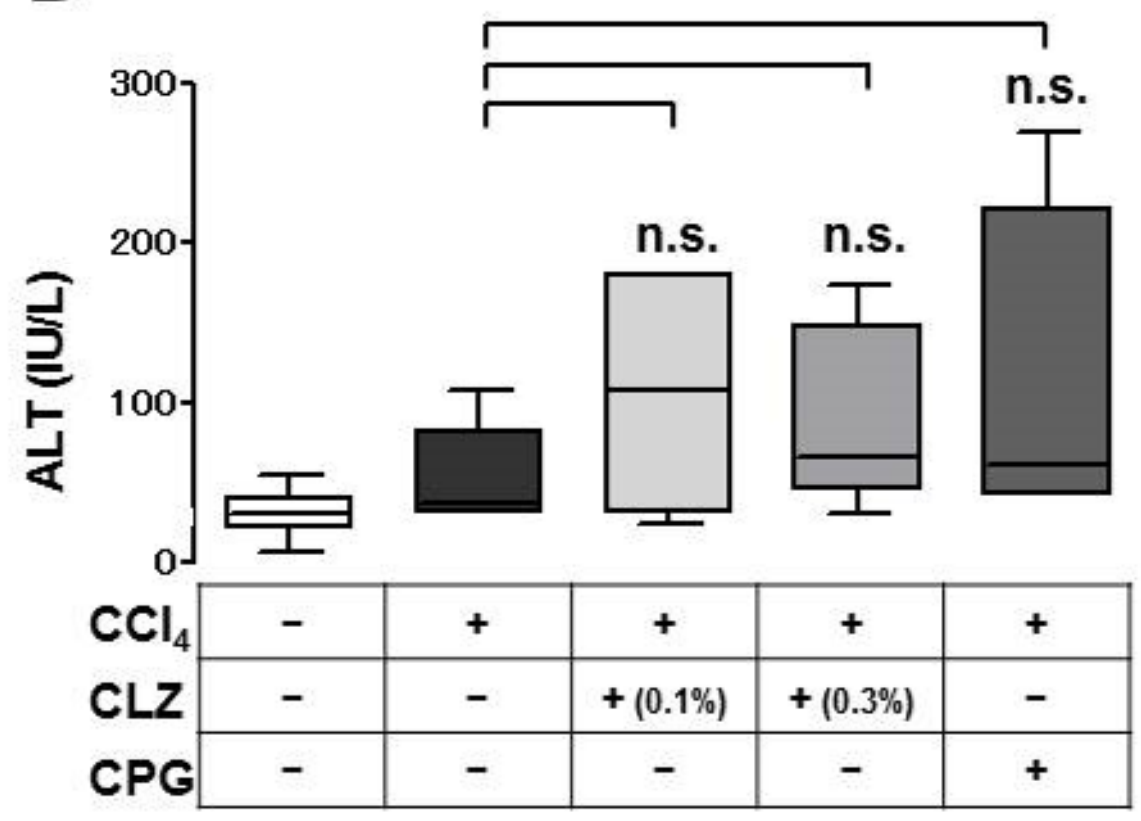

Figure 3 
E

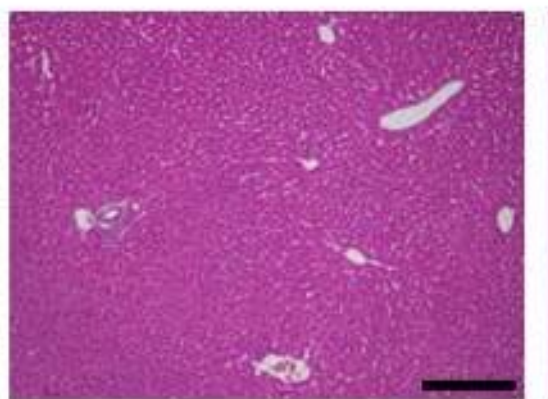

$\mathrm{CCl}_{4}(-)$

Control diet

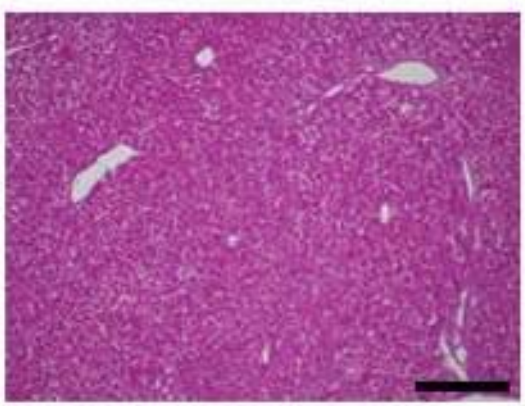

$\mathrm{CCl}_{4}(+)$

$0.1 \% \mathrm{CLZ}$

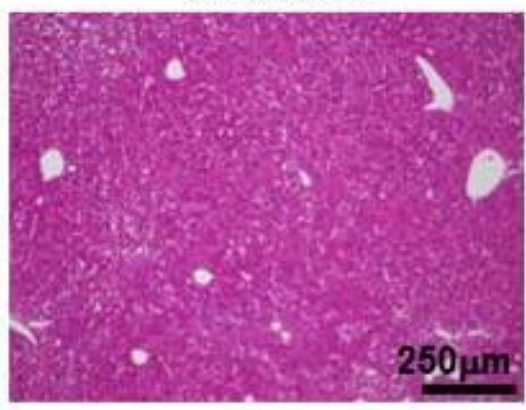

$\mathrm{CCl}_{4}(+)$

CPG
F

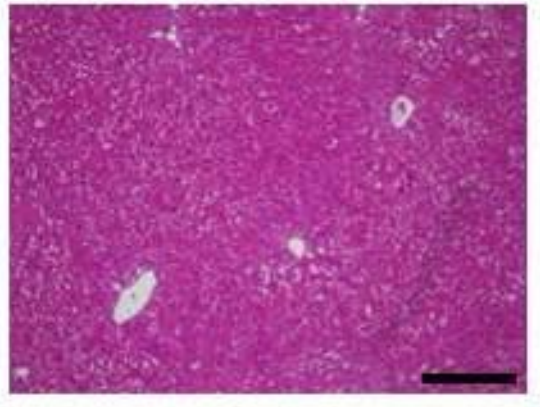

$\mathrm{CCl}_{4}(+)$

Control diet

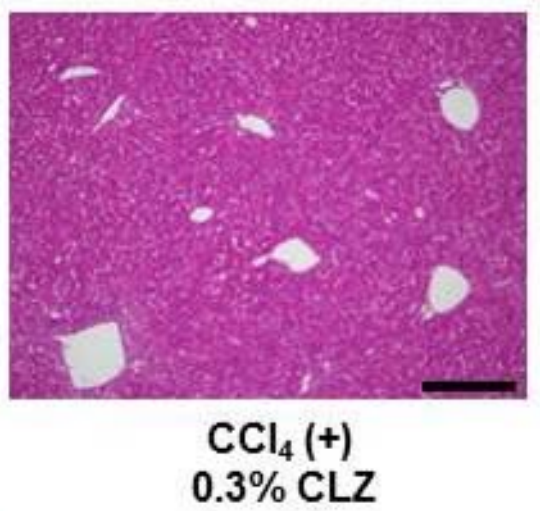

$0.3 \% \mathrm{CLZ}$

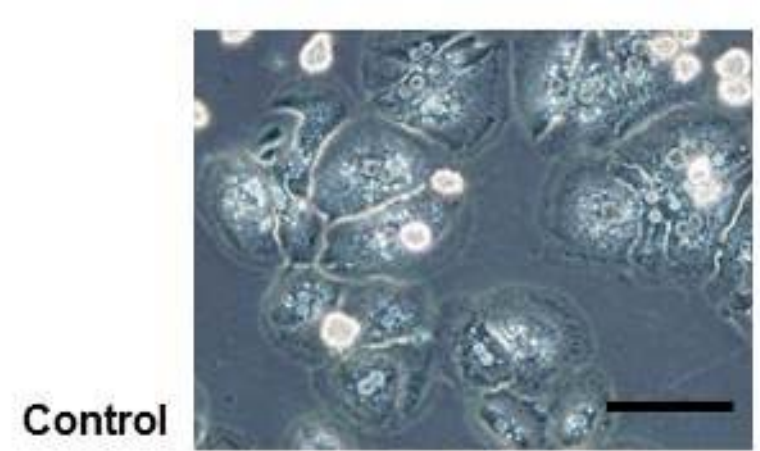

$5 \mu \mathrm{M}$ CLZ

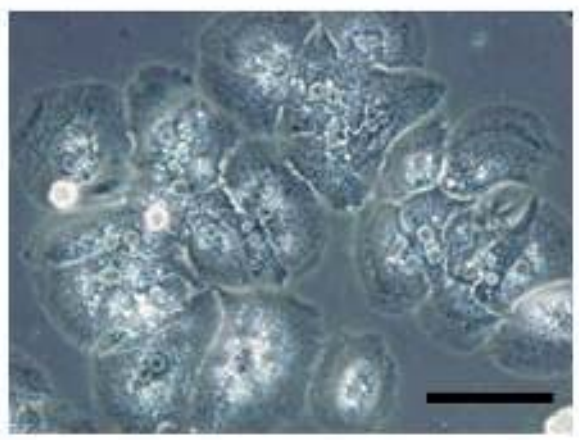

$15 \mu \mathrm{M}$ CLZ

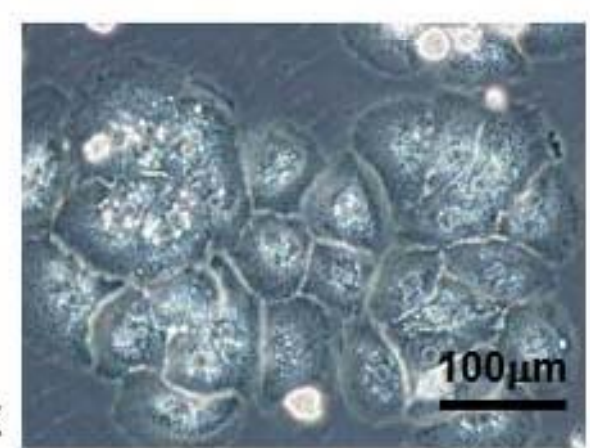

Figure 3 
A
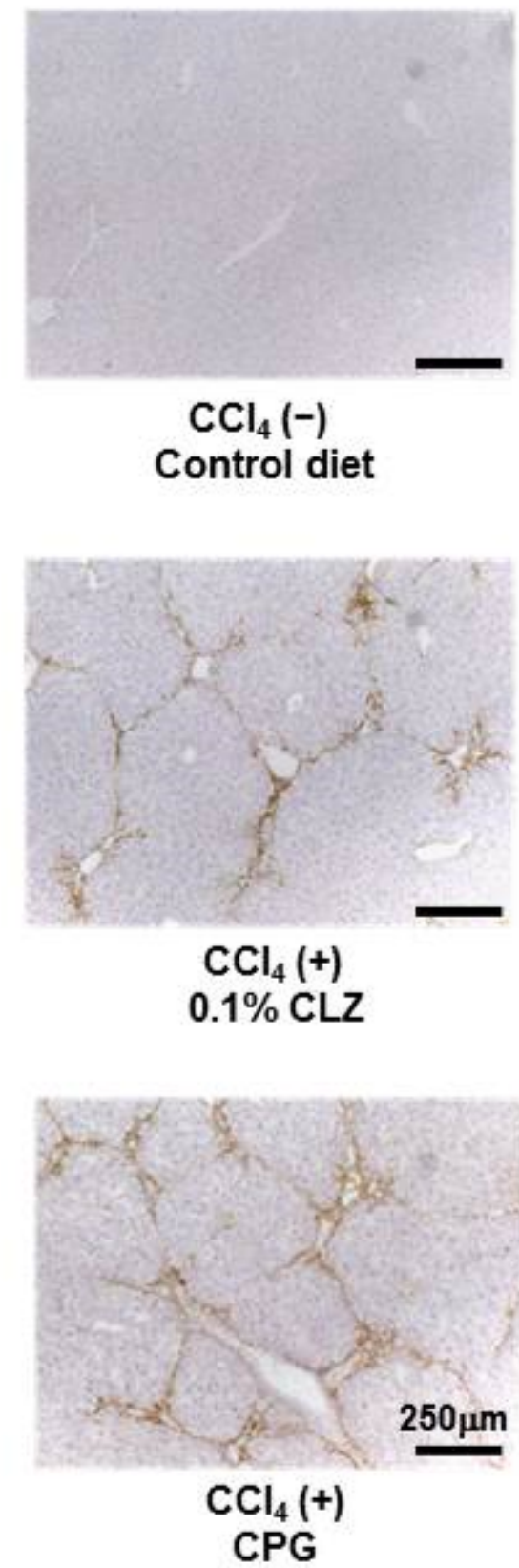

B
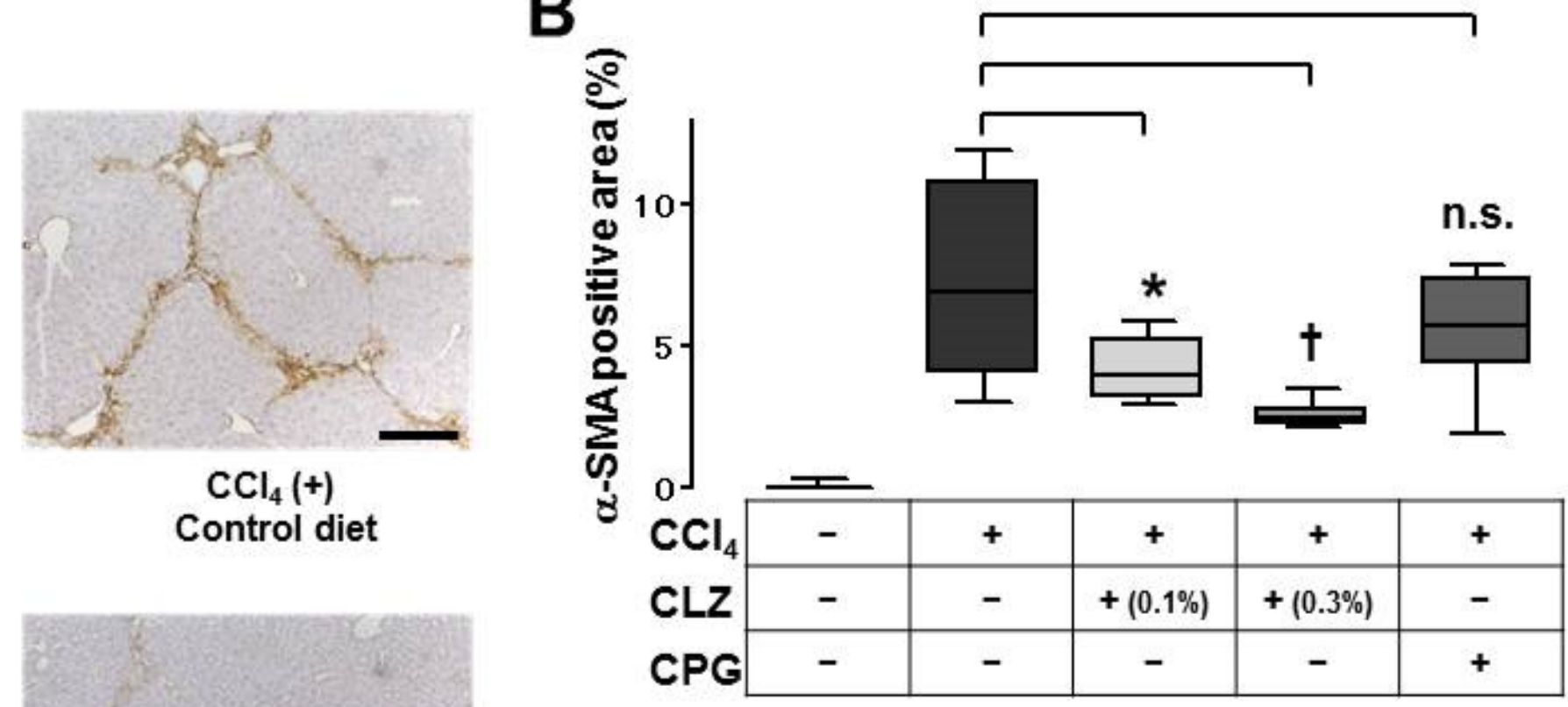

C
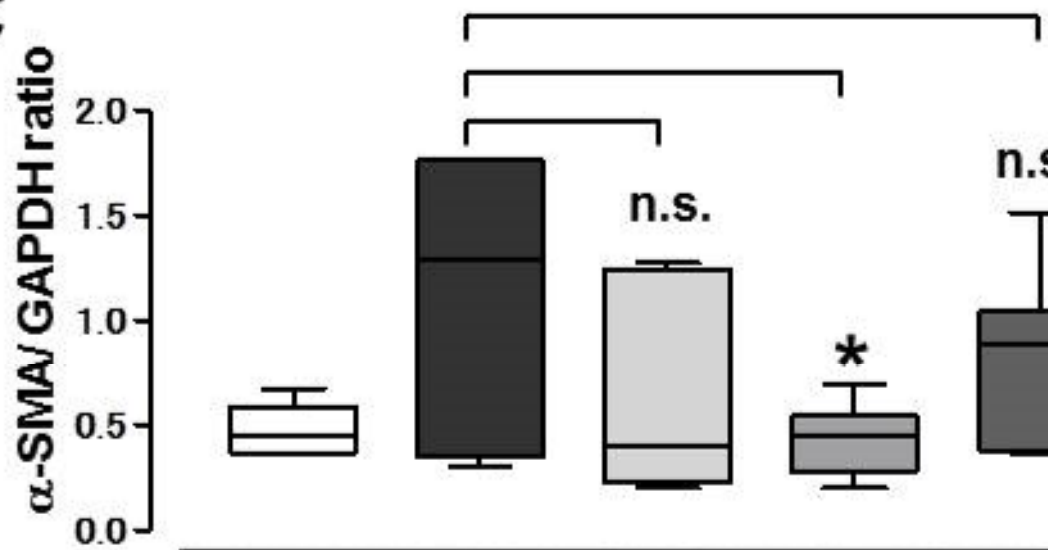

n.s.

\section{$\mathrm{CCl}_{4}(+)$}

$0.3 \% \mathrm{CLZ}$

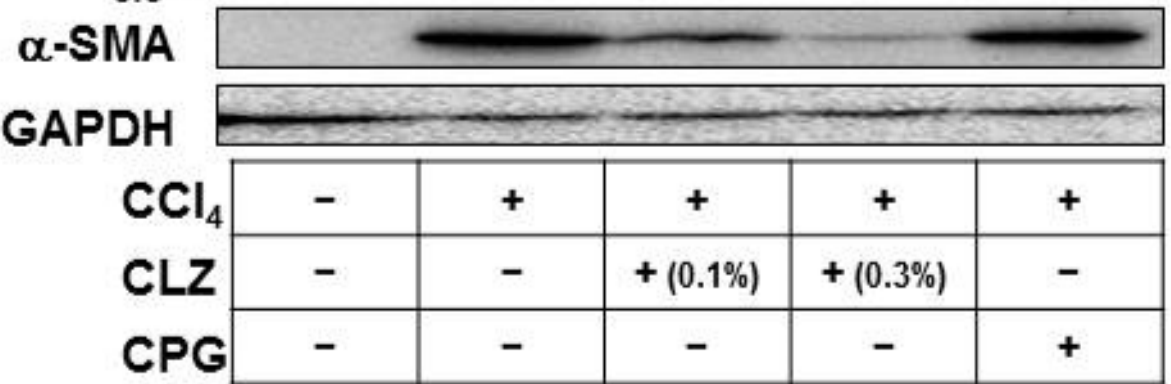

Figure 4 
A

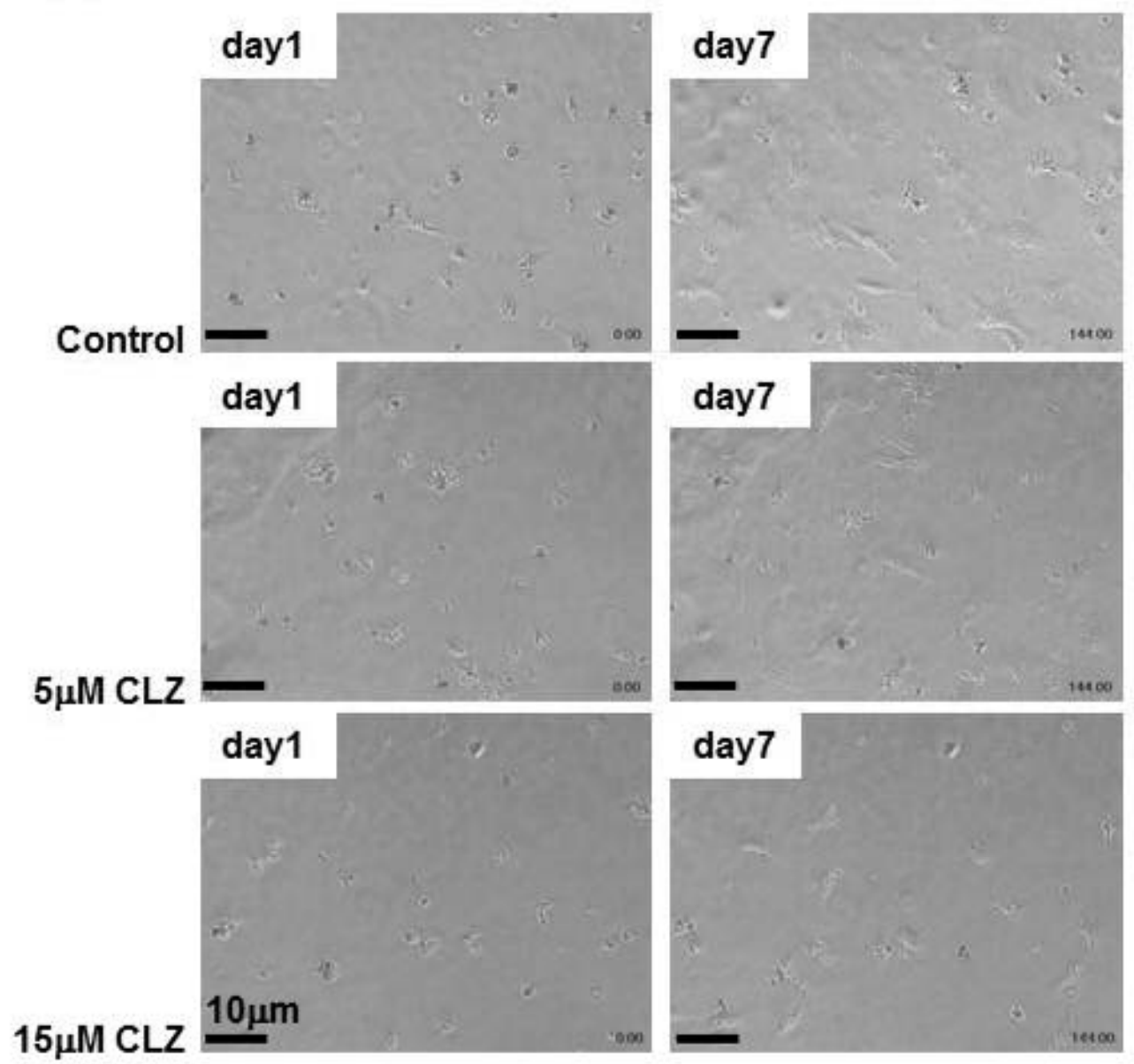

B

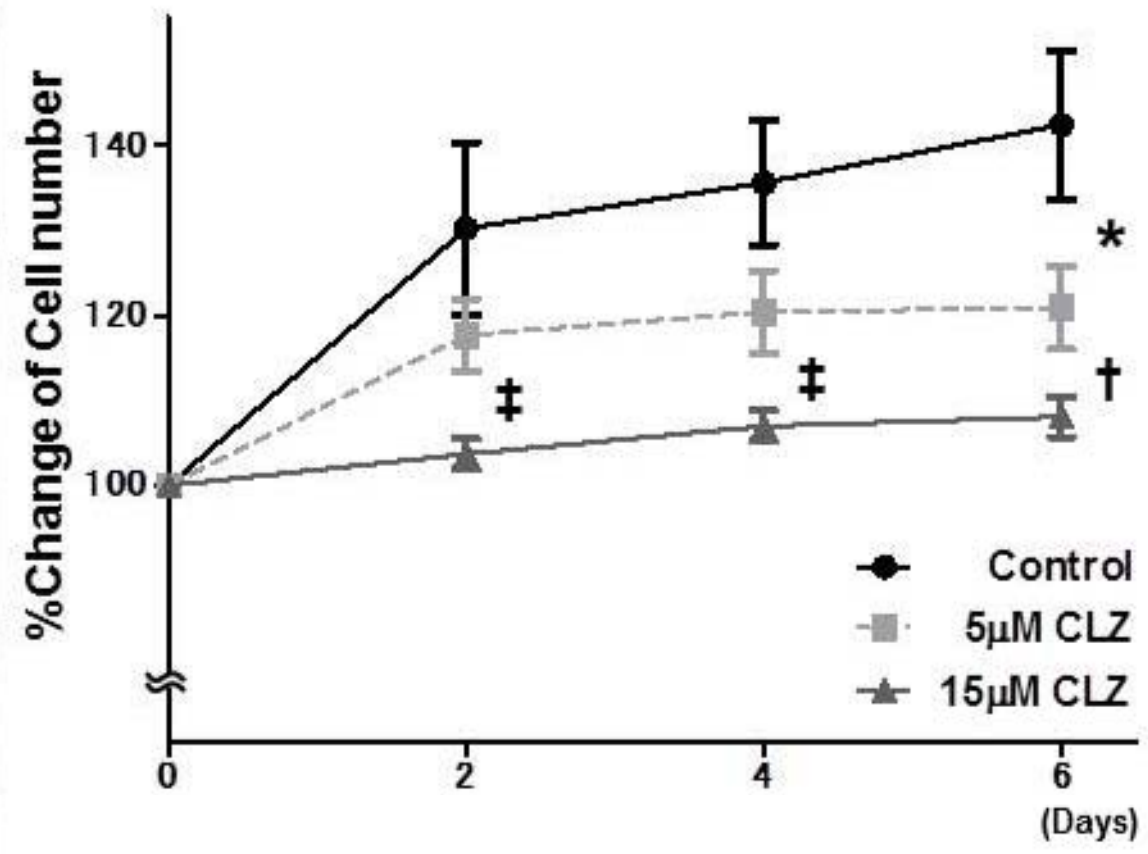

Figure 5 
C

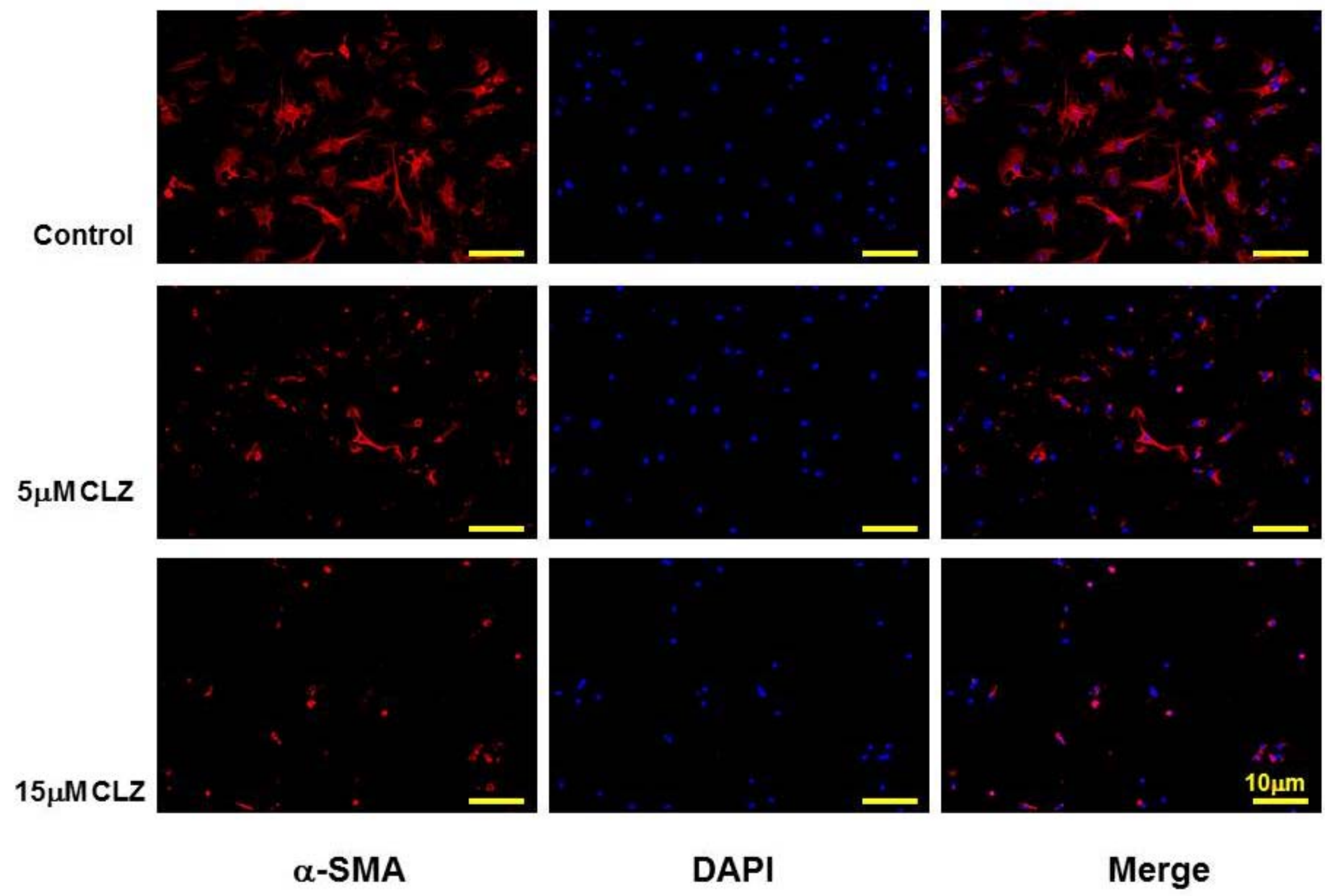

Figure 5 
D

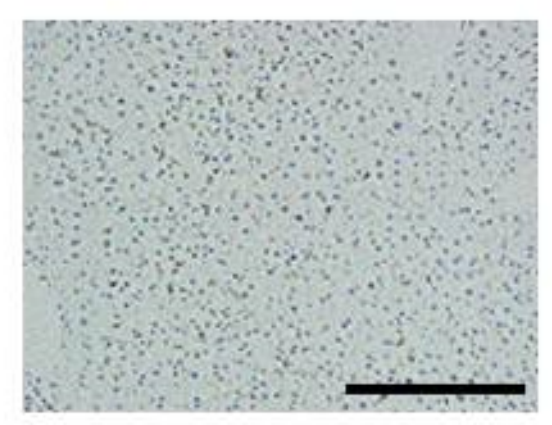
$\mathrm{CCl}_{4}(-)$

Control diet

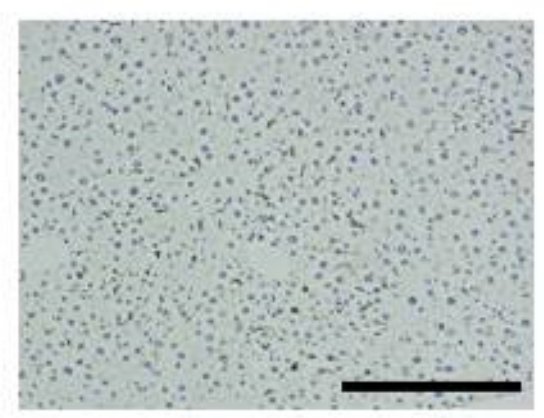

$\mathrm{CCl}_{4}(+)$

$0.1 \% \mathrm{CLZ}$

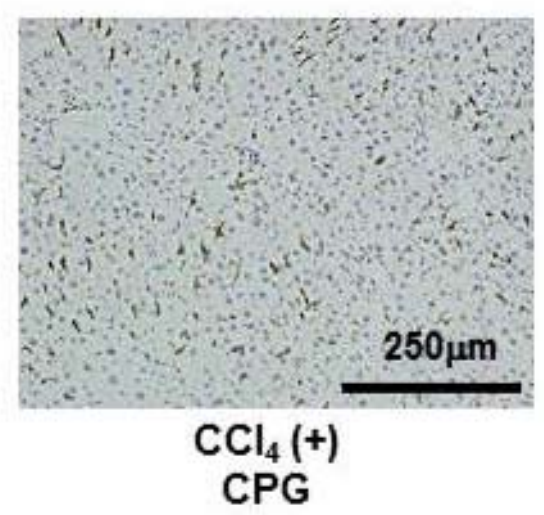

E

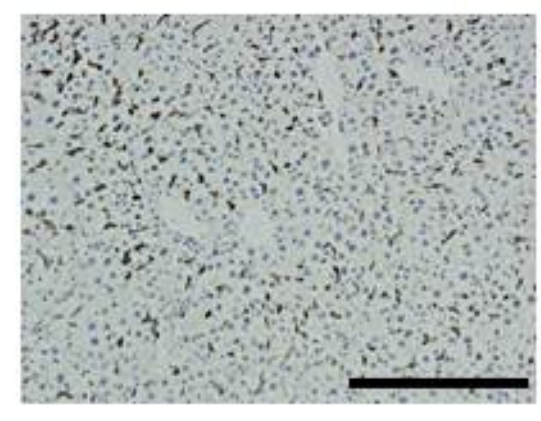
$\mathrm{CCl}_{4}(+)$ Control diet

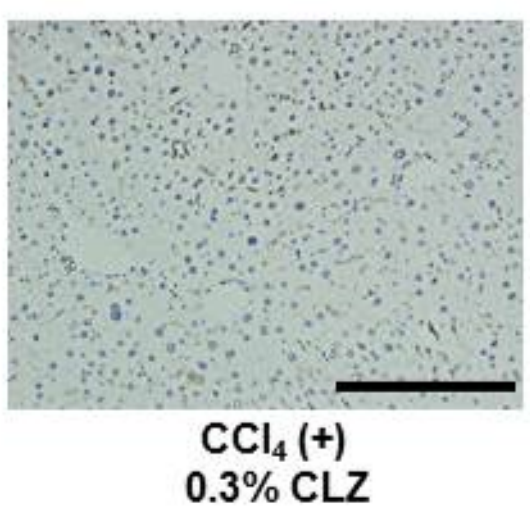


F
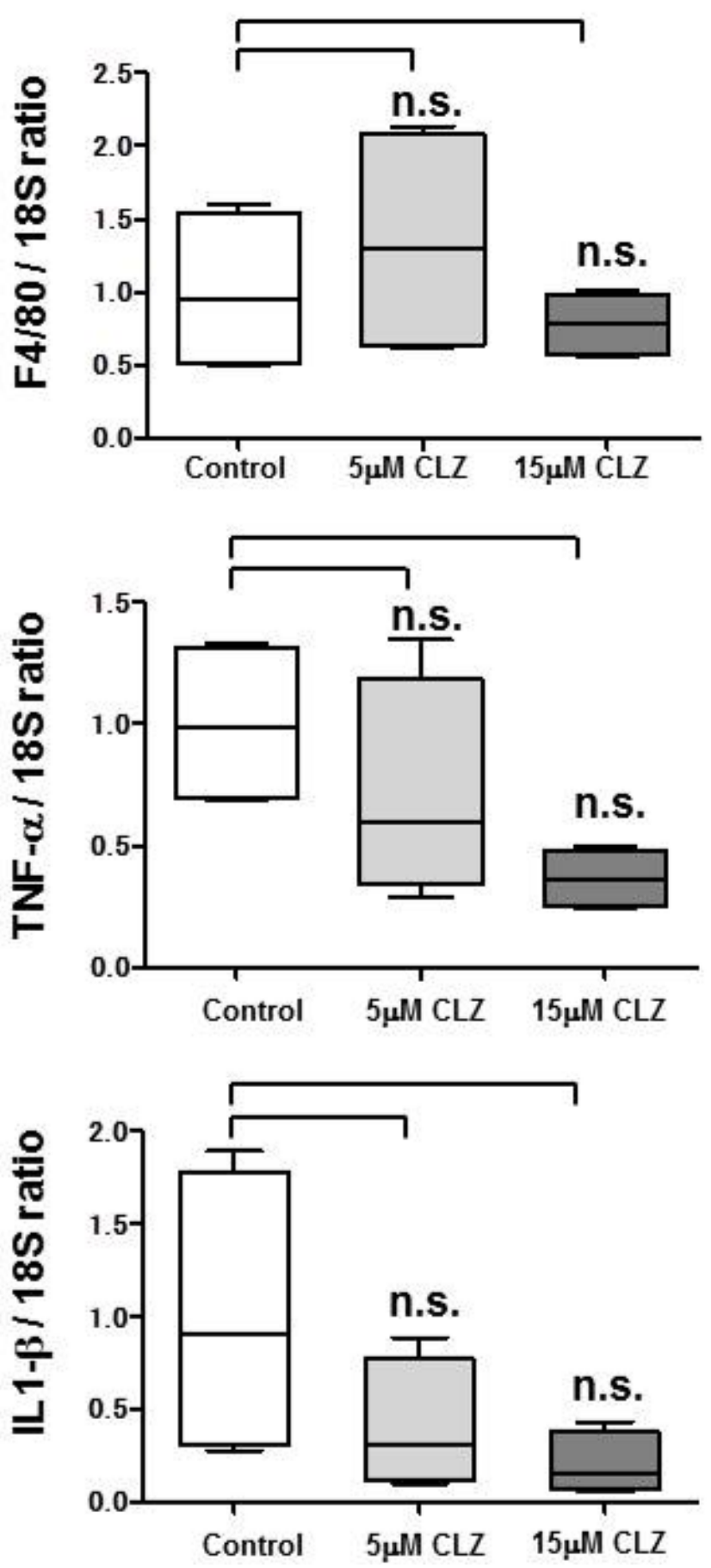
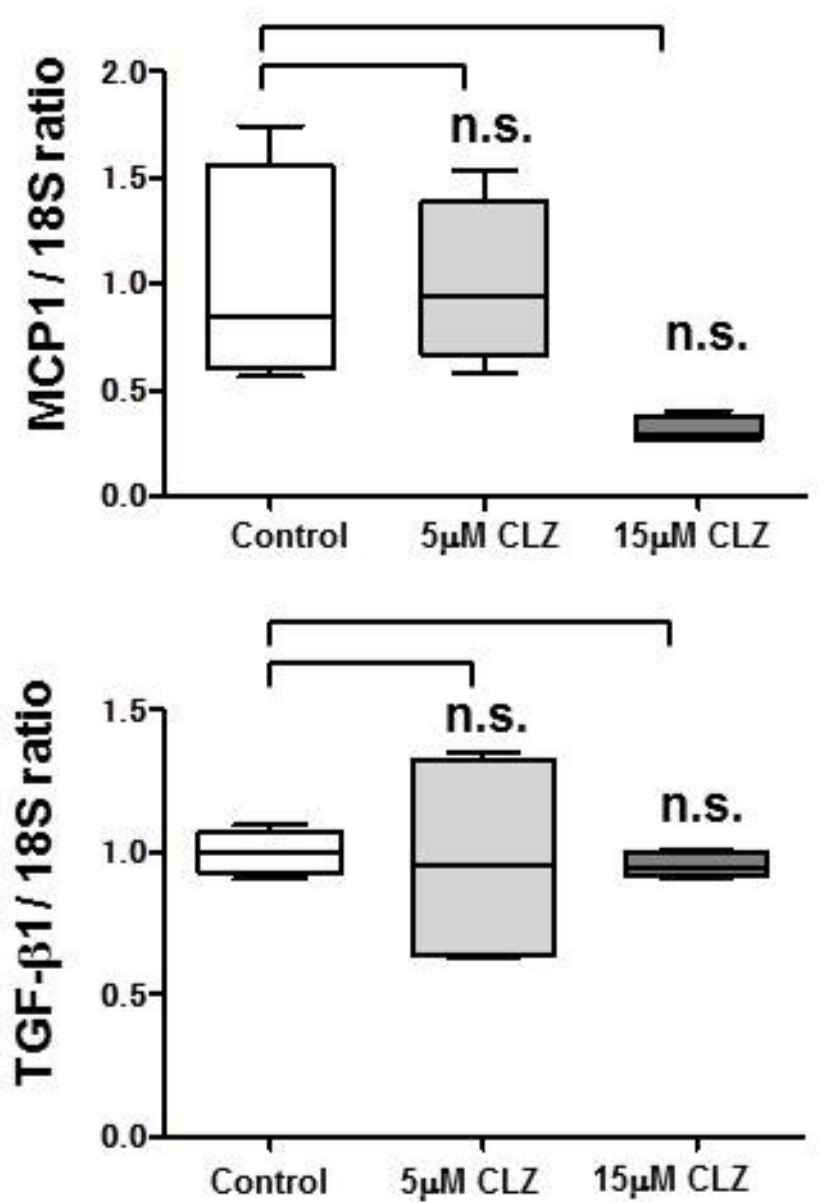

Figure 5 
G
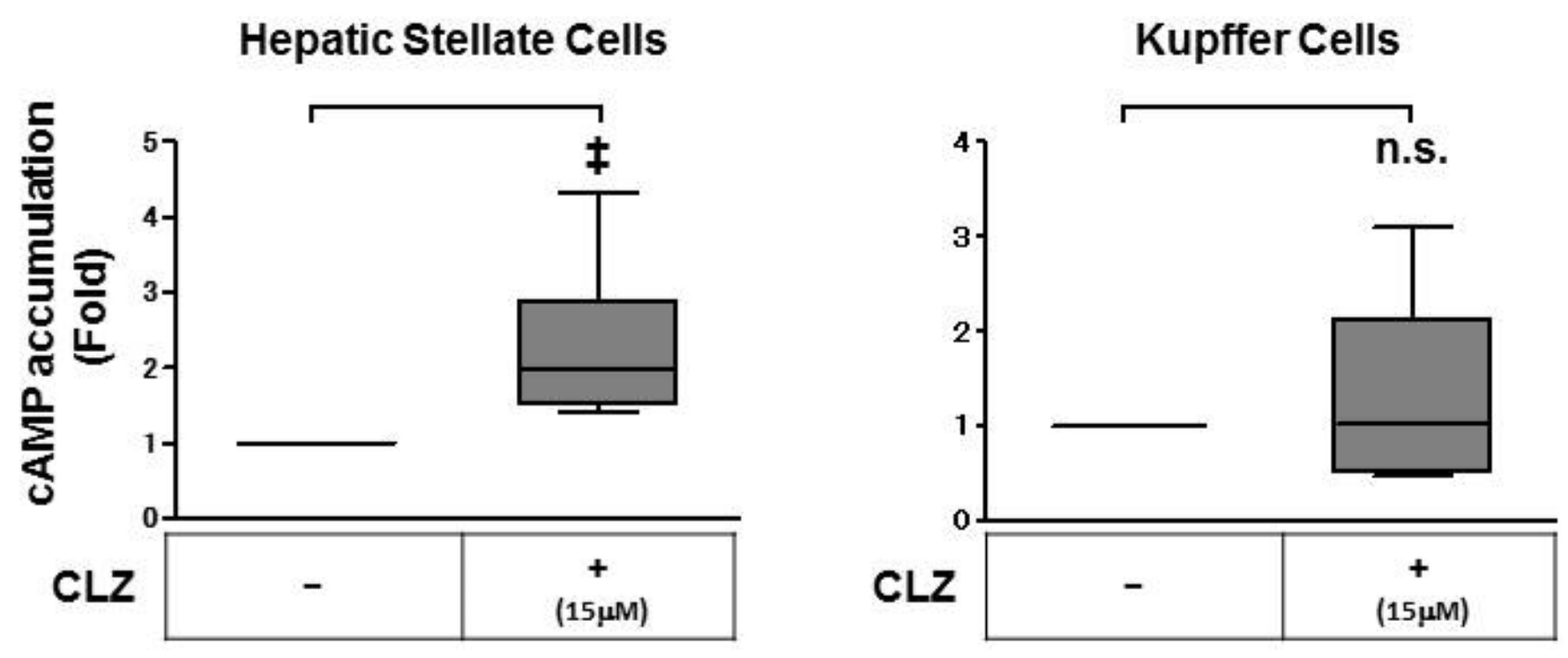

Figure 5 
A

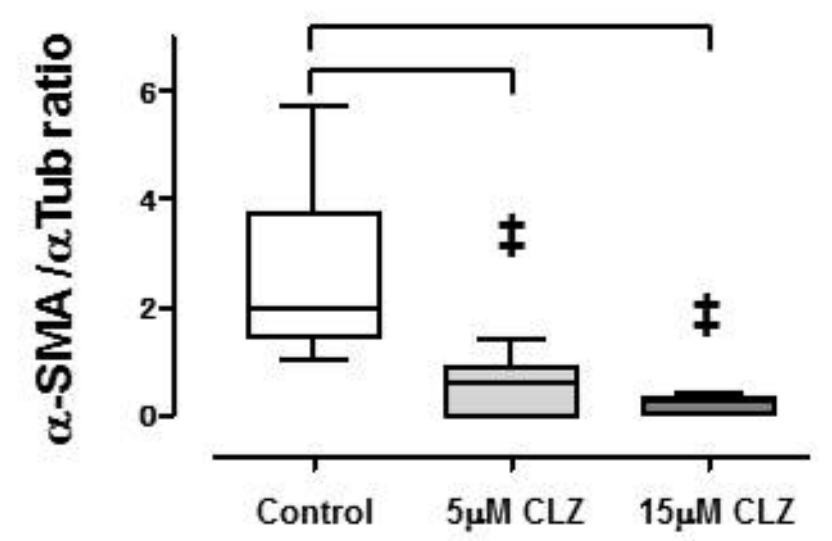

B

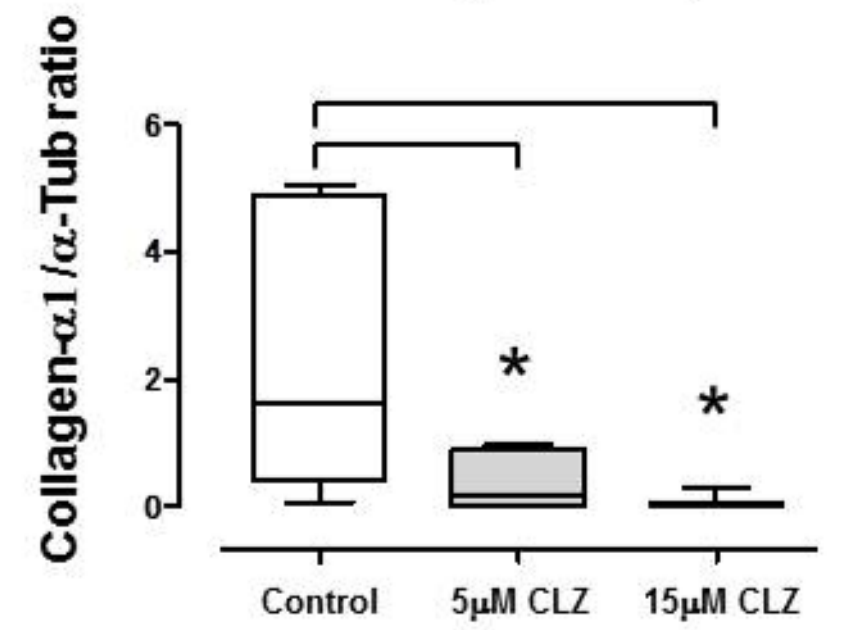

C

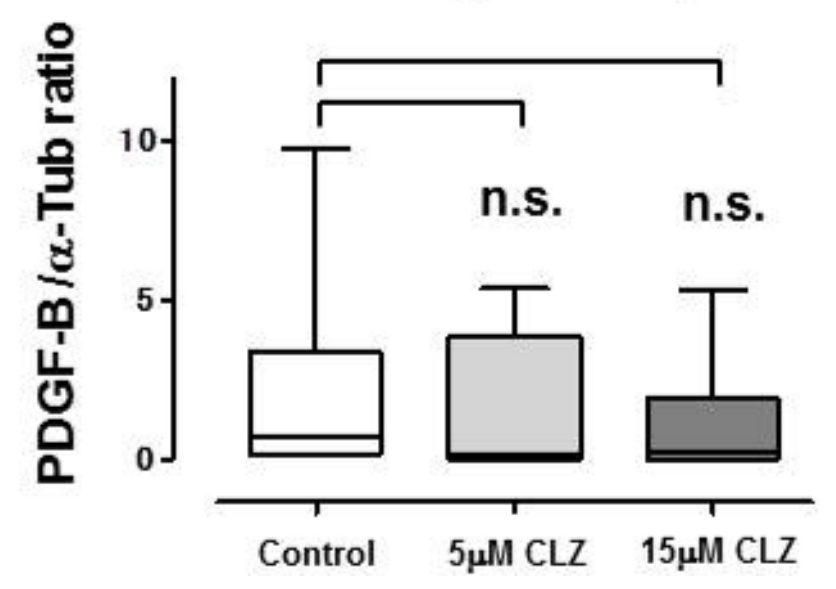

D

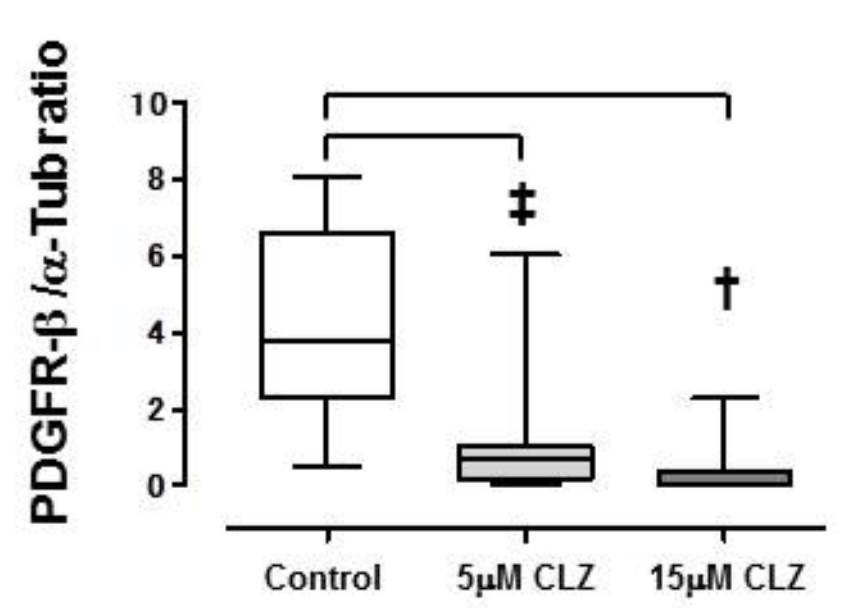

E

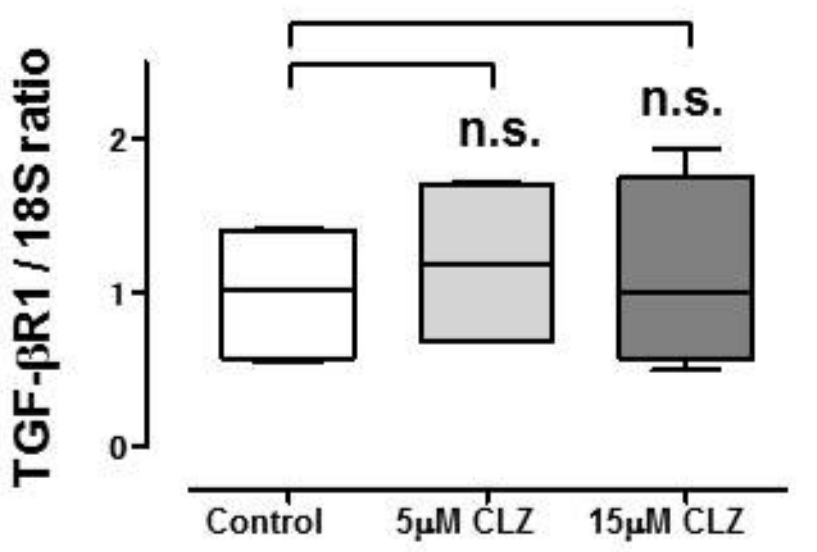

